Originalveröffentlichung in: Zenck, Martin ; Jüngling, Markus (Hrsgg.): Erzeugen und Nachvollziehen von Sinn : rationale, performative und mimetische Verstehensbegriffe in den Kulturwissenschaften, München u.a. 2011, S. 363-392

\author{
HENRY KEAZOR
}

\title{
„...nur im Unterschied liegt der Reiz“: Claude Debussys und Victor Segalens Opernprojekt Orphée-Roi
}

\section{Abstract}

Zwischen 1907 and 1915 verfasste der Schriftsteller, Arzt und Ethnologe Victor Segalen in Zusammenarbeit mit Claude Debussy das Libretto zu der in der Folge nie realisierten Oper Orphée-Roi. Da die 1921 erfolgte Edition des Textes jedoch bis 1961 nicht problemlos konsultierbar war, wurde das Projekt überwiegend in jenen Studien vernachlässigt, die sich mit dem Werk der beiden Künstler auseinandersetzen bzw. sich der Überlieferungs- und Rezeptionsgeschichte des Orpheus-Stoffes widmen. Doch gerade diese Themenbereiche profitieren von einer Untersuchung des Orphée-Roi, da sie einen wesentlichen Beitrag zum Verständnis von Segalens Konzept einer „Ästhetik des Diversen“ leistet, sowie zu Debussys Versuchen, aus dem Schatten seiner Oper Pelléas et Mélisande (1902) herauszutreten, und vor allem die Veränderungen aufzeigen kann, denen der Orpheus-Mythos zu Beginn des 20. Jahrhunderts unterzogen wird, wenn Segalen ihn unter dem Aspekt synästhetischer Wahrnehmung gestaltet. Diese Neu-Interpretation macht das Opernprojekt zu einem idealen Untersuchungsgegenstand im Kontext der Frage nach Verstehensbegriffen und Sinnkonstruktionen. Denn hinter Segalens und Debussys Adaption steht das Bestreben, den tradierten Orpheus-Mythos der eigenen Ästhetik gemäß zu verstehen, und das heißt hier auch: aus ihm das Benötigte herauszuhören bzw. ihn den eigenen Anforderungen entsprechend zu überschreiben, zu ergänzen. Zugleich wird das Verstehen im Orphée-Roi selbst zum Thema gemacht, denn Grundkonflikt der Handlung ist die zumeist scheiternde Kommunikation zwischen dem sich nur durch musikalische Klänge mitteilenden Orpheus und den Worte ausspuckenden Menschen. Aus dieser Opposition zwischen Musik und Sprache gestaltet Segalen das Thema der Alterität aus. Doch obwohl mit der Gestalt der Eurydice eine Vermittlungsfigur auftritt, kann und soll der Ausgleich gar nicht dauerhaft stattfinden, denn es ist gerade die ewige Spannung zwischen sich fremden Entitäten, die Segalen zufolge erst die Chance zur bewussten und stets neuen Wahrnehmung der Welt eröffnet. 
Das Seltsame aber ist, daß die antiken Mythen zu fast allen Zeiten anders gesehen und gedeutet wurden. Seit der Wiederentdeckung der Antike in der Renaissance haben alle Epochen die Gestalten und Begebenheiten der antiken Mythologie adaptiert und umgeschmolzen, so daß die archaischen Symbole nur den Geist der Epoche spiegelten, die sie benutzte. Das ist im Grunde ganz natürlich und zeugt von der schöpferischen Kraft der sich ablösenden Generationen, die das eigene Daseinserleben in den antiken Stoff transfigurieren, andererseits die archetypischen Wahrheiten der antiken Mythologie in die lebendig erfüllte Gegenwart einschmelzen.

Horst Goerges: „Wandlungen des Orpheus-Mythos auf dem musikalischen Theater “1

\section{Diesseits und Jenseits der Hermeneutik?}

Diesseits der Hermeneutik - unter diesem Titel hat Hans Ulrich Gumbrecht 2004 in Deutschland sein kurz zuvor auf Englisch erschienenes Buch veröffentlicht. Im Vorwort zur deutschen Ausgabe erklärt der Autor, weshalb diese nun unter einem deutlich anderen Namen firmiert als die wenige Monate zuvor publizierte Originalausgabe, die „Production of Presence“ überschrieben war: Ursprünglich habe er das Buch "The Non-Hermeneutic" betiteln wollen, doch ein befreundeter Kollege habe ihn davon abgebracht, da er einem unter dieser Überschrift verkauften Buch selbst unter den interessierten Lesern in Amerika kaum eine Chance geben mochte. ${ }^{2}$ Das ihm gegenüber in Deutschland geäußerte Bedauern darüber, dass der Begriff Hermeneutik aus dem Titel getilgt worden war, habe Gumbrecht umgekehrt - wieder dazu gebracht, beinahe zur ursprünglichen Überschrift zurückzukehren. ${ }^{3}$ Allerdings hatte sich seine Perspektive nun insofern geschärft, als die Wissenschaft von der Interpretation nun nicht mehr - wie es im Falle von "The Non-Hermeneutics" noch geschehen wäre - einfach nur negiert wurde, sondern ihr wurde nun vielmehr eine Position gegenübergestellt, die eben als „diesseits" der Interpretation definiert werden soll. Gumbrecht beeilte sich dabei, eigens darauf hinzuweisen, dass damit nicht etwa ein Standpunkt „auf der Seite der Hermeneutik" gemeint sei ${ }^{4}$. Ganz im Gegenteil (und unter Bewahrung der im ursprünglichen Titel formulierten Opposition) operiert die in dem Buch entworfene Perspektive mit einem Dualismus, demzufolge die Hermeneutik und ihre Leistungen, die Interpretation, sozusagen schon das Toten- und Schattenreich, das Jenseits, der Dinge darstellen, die im von Deutungen und Auslegungen gänzlich unangetasteten Leben, im Diesseits, erfahren und genossen werden können. Eine solche, sozusagen eschatologisch gefärbte Beschreibung von Gumbrechts

1 Aus dem Programmheft der Bayerischen Staatsoper zu Glucks „Orfeo ed Euridice“ 1983, zitiert nach: Attila Csampai u. Dietmar Holland (Hg.): Claudio Monteverdi, Orfeo/Christoph Willibald Gluck, Orpheus und Eurydike - Texte, Materialien, Kommentare. Reinbek bei Hamburg 1988, S. 23-26, hier: S. 23.

2 Hans Ulrich Gumbrecht: Diesseits der Hermeneutik. Frankfurt a.M. 2004, S. 9.

3 Ebd., S. 9-10.

4 Ebd., S. 10 , 
Denkschema mag dabei zunächst polemisch zugespitzt erscheinen; tatsächlich aber legt sie lediglich den Blick auf die assoziativen Quellen der Begriffsoppositionen frei, mit denen der Autor operiert: Hier die „ungeistige“ Körperlichkeit, Materialität und Präsenz des Lebens; dort hingegen die intellektuelle Immaterialität, Abstraktion und Geisterhaftigkeit der den Phänomenen Sinn zuweisenden (und sie damit gleichsam ertötenden) Deutung. ${ }^{5}$

Zwar weiß Gumbrecht dabei durchaus zu differenzieren: So nimmt die „Erfahrung" (vom Autor verstanden als Weltaneignung durch intellektuelle, sinnstiftende Begriffe) den körperlich "wahrgenommenen“" (d.h. hier: alleine durch die Sinne erfassten) Dingen der Welt nicht gleich vollständig das Leben - jedoch: „Wenn man einem präsenten Ding einen Sinn zuschreibt (...), vermindert man offenbar die Wirkung, die dieses Ding auf die eigenen Sinnesorgane haben mag. ${ }^{\text {" }}$ Doch erstaunlicherweise zieht der Verfasser damit zunächst einmal nicht die Möglichkeit in Betracht, dass eine solche Sinnzuweisung gerade zu einem intensiveren, da bewussteren Erleben des so „wahrgenommenen“ UND „erlebten“ Gegenstandes führen könnte. Da Gumbrecht sinnstiftende „Erfahrung“ offenbar nur in Konkurrenz zur "Wahrnehmung", als blasses Abbild und abstraktes Surrogat des durch die Deutung verdrängten Originals, sieht, ${ }^{7}$ vermag er sich ein solches, durch Begriffe fokussiertes und damit verstärktes Erleben vorerst nicht vorzustellen. Dies hat möglicherweise seinen Grund in dem Umstand, dass Gumbrecht sich z.T. darauf beschränkt, die von ihm (teilweise nicht zu Unrecht) beklagten Entwicklungen im Verhältnis von Präsenz und Sinn einfach umzukehren: Wurde dem Sinn der Phänomene von der Metaphysik ein höherer Wert zugeschrieben als ihrer materiellen Präsenz, so versucht der Autor schlichtweg eine Umstülpung dieser Rangordnung. Höchstes Ziel der Geisteswissenschaften ${ }^{8}$ soll es ihm zufolge nun nicht länger sein, Präsenz zugunsten der Sinnzuschreibung abzuwerten, preiszugeben und zu verdrängen, ${ }^{9}$ sondern - umgekehrt - gerade das Verlangen nach ihr zu erwecken!

Der Autor ist freilich zu klug, um nicht selbst zu bemerken, dass er sich damit ein paradoxes Ziel gesetzt hat, das nur in einer Aporie enden kann: Denn schon eine bewusste Strategie entwickeln zu wollen, die gewährleistet, dass das Materielle möglichst unreflektiert in die angestellte Betrachtung mit einfließen kann, erscheint in sich widersprüchlich genug; in diesem Zusammenhang aber auch noch Begriffe finden zu wollen, die es ermöglichen, mit der Welt in eine Beziehung zu treten, die

5 In fast noch demgegenüber gesteigerten $\mathrm{Maß}$ liegt dieser Dualismus bereits Susan Sontags Essay „Against interpretation“ von 1964 zugrunde, wo der sterilen Interpretation das Ideal einer „erotics of art " gegenübergestellt wird. Vgl. Susan Sontag: Against interpretation and other essays. New York 1967, S. 3-14, hier: S. 14.

6 Gumbrecht: Diesseits der Hermeneutik, S. 11.

7 Dies sozusagen die negative Umkehrung des von Jean-Luc Nancy: The Birth of Presence, Stanford 1993, S. 6, beschworenen (und von Gumbrecht, ebd., S. 77, eben so zitierten) Verhältnisses: „Die Präsenz kommt nicht, ohne jene Präsenz auszulöschen, welche die Repräsentation bezeichnen möchte".

8 Gumbrecht: Diesseits der Hermeneutik, S. 17.

9 Ebd., S. 12. 
nicht durch Sinnzuweisung strukturiert ist, bedeutet dann endgültig, sich die Quadratur des Kreises zum Projekt zu nehmen, denn gewonnen werden soll hier folglich nichts weniger als sinnunabhängige Begriffe. ${ }^{10}$ Auch hier erweist sich Gumbrecht als durch die lang ausgeübte Macht der Interpretation so ermüdet, dass er sein Heil vor ihr nur in ihrer direkten Umkehrung zu sehen vermag, während tatsächlich jede Auseinandersetzung mit einem Phänomen ohnehin erst einmal dadurch eröffnet wird, dass dieses mit seiner Präsenz auf uns wirkt, und wir erst sodann, im Gefolge einer unterschiedlich langen Beschäftigung, ${ }^{11}$ damit beginnen, sinnstiftende Begriffe zu entwickeln. ${ }^{12}$

Der Verfasser flüchtet sich daher im weiteren Verlauf des Buches nicht nur zunehmend in Ironie, ${ }^{13}$ sondern er schwenkt auch ganz offen in einen versöhnlichen Kurs ein, den er sich vom Begriff der Komplementarität weisen lässt. Die Stillung des Verlangens nach Präsenz, das wird schnell erkannt, „lässt sich jedoch nicht dadurch erreichen, dass die Präsenz einfach an die Stelle des Sinns tritt. Letzten Endes wird in diesem Buch ein Verhältnis zu den Dingen dieser Welt befürwortet, das zwischen Präsenz- und Sinneffekten oszillieren könnte“. ${ }^{14}$ "Aus dieser Gesinnung heraus wird das Buch beispielsweise empfehlen, wir sollten das ästhetische Erleben als ein Oszillieren (und mitunter auch als Interferenz) zwischen ,Präsenzeffekten und ,Sinneffekten' begreifen. "15 Im weiteren Verlauf verdichten und präzisieren sich diese Überlegungen zu der Einsicht: „Präsenz und Sinn treten jedoch stets zusammen auf und stehen immer in einem Spannungsverhältnis zueinander "16, dessen Ponderierung dadurch bestimmt wird, „dass es im Verhältnis zwischen Sinnund Präsenzkomponente stets zu spezifischen Verteilungen kommen wird, die von der Materialität (d.h. der medienspezifischen Modalität) jedes Gegenstandes ästhetischen Erlebens abhängen ". ${ }^{17}$

10 Ebd., S. 71, formuliert auch den „auf den ersten Blick“ gehegten Zweifel an der Möglichkeit, solche Begriffe zu präsentieren - da deren Präsentation jedoch auch im weiteren Verlauf des Buches ausbleibt, scheint sich diese Skepsis zu begründen.

11 Natürlich bezieht sich Gumbrechts Kritik auch darauf, dass ihm zufolge diese „begriffliche Reaktionszeit" zu kurz und zunehmend kürzer sei, so dass wir die Dinge gar nicht mehr erst auf uns wirken lassen, sondern sie sogleich intellektuell parieren und damit von uns fernhalten.

12 Hans-Thies Lehmann: „Über die Wünschbarkeit einer Kunst des Nichtverstehens (Ästhetik. Eine Kolumne) “, in: Merkur. Deutsche Zeitschrift für europäisches Denken, Nr. 542, Heft 5, 48. Jg., Mai 1994, S. 426-431, hier: S. 429, hat diese Prozessabfolge in seiner verlangsamten Form bereits zur Grundlage einer „Poetik des Aufmerkens“ genommen, „das den Reiz speichert, im Vorbewussten hält, ihm eine flüchtige Einschreibung im Wahrnehmungsapparat ermöglicht, ohne ihm im Akt des Verstehens verpuffen zu lassen: Gedächtnisspur anstelle von Bewußtsein, das Verstehen aufgeschoben."

13 Schon die häufigen Selbst- und Verweise deuten dies an; abgesehen von Beispielen für zu vermittelnde Momente der Intensität (S. 118: der Anblick einer schönen Bibliotheksmitbenutzerin oder der Touchdown-Pass des Football-Quaterbacks) deutet Gumbrecht: Diesseits der Hermeneutik, S. 168, schließlich auch noch selbst auf den Gestus der Selbstironie hin.

14 Gumbrecht: Diesseits der Hermeneutik, S. 12.

15 Ebd., S. 18; so dann auch S. 127-128.

16 Ebd., S. 126.

17 Ebd., S. 130. 
In letzter Instanz bedeutet dies folglich: Sinn, Bezeichnung und Interpretation sollen doch nicht preisgegeben werden, denn die Interpretation erweist sich zuletzt doch als ein „elementares und wahrscheinlich unvermeidbares theoretisches Verfahren ", ${ }^{18}$ und das bescheidener formulierte Ziel besteht nun darin, Begriffe auszuprobieren und zu entwickeln, „die uns in den Geisteswissenschaften die Möglichkeit geben könnten, zur Welt in ein Verhältnis zu treten, das komplexer ist als die Interpretation allein (... $)^{\text {. }}{ }^{19}$

Obgleich der zunächst erhobene, radikaler gefärbte Anspruch damit stark zurückgefahren wird und Gumbrecht zuletzt doch wieder nur den korrigierenden Ausgleich zwischen Präsenz und Sinn anstrebt (nachdem zunächst grundsätzlich eine Alternative zu dem daraus resultierenden Subjekt/Objekt-Paradigma gefordert worden war) ${ }^{20}$ wäre zu prüfen, ob sein Modell nicht in modifizierter Form und mit weniger durchgreifenden Ambitionen gerade im Bereich der Interpretation anwendbar ist. Denn die Interpretationsmüdigkeit Gumbrechts, aus der sein leidenschaftliches Plädoyer für eine Einstellung resultiert, die wieder die „Produktion von Präsenz" (dies auch der deutsche Untertitel seines Buches) ${ }^{21}$ fördert, ließe sich auch mit jenen Momenten innerhalb der Geschichte der Wissenschaften und Künste in Beziehung setzen, in denen eine lange Tradition von Deutungen, Interpretationen, Bearbeitungen und Sinnzuweisungen den direkten Zugang zu einem ursprünglichen Stoff, einem Thema oder Gegenstand zu verstellen droht: Einem Palimpsest ähnlich dient ihr eigentliches Fundament nur noch als Träger mehrerer, sich überlagernder Schichten, durch die das Original nur gelegentlich und dann verzerrt hindurch schimmert ${ }^{22}$ - sofern es nicht ohnehin schon durch die Lagen der diversen Variationen, Zurichtungen und Abwandlungen ganz zugedeckt wurde. Die Sehnsucht nach einem „Diesseits der Hermeneutik“ wäre von daher weniger als Rückeroberung des materiellen Kontakts mit einer Sache zu verstehen, denn vielmehr als Verlangen nach einer Rückkehr zu den Quellen, z.B. eines Mythos, einer Geschichte, eines Sujets; Gumbrechts Ruf nach Präsenz könnte so auch als befreiendes „Ad fontes!“ umgedeutet werden, das nicht einem zwingend physi-

18 Ebd., S. 71.

19 Ebd. Diese Begriffe werden nun als „nichtinterpretativ“ charakterisiert.

20 Ebd., S. 76: „Genau dies ist der Grund, weshalb ich glaube, daß wir den Versuch machen sollten, unseren Kontakt zu den Dingen der Welt außerhalb des Subjekt/Objekt-Paradigmas (oder einer modifizierten Spielart dieses Paradigmas) wiederherzustellen und die Interpretation zu meiden (...)."

21 In der englischen Originalausgabe fungiert er („Production of Presence“) als Hauptüberschrift, der Untertitel lautet hier "What meaning cannot convey“.

22 Vgl. dazu auch den Gedanken Georges Steiners, dass "toute grande création est critique par rapport aux chef-d'oeuvre qui l'ont précédé. José Ferrater Mora hat dies dergestalt formuliert: „Au fur et à mesure que chaque nouvelle action se superpose aux précédentes, ces dernières sont substantiellement modifiées parce que l'action qui s'ajoute concorde profondément avec celle qui existait déjà, paraissait être implicite et nécessiter qu’elle se développe uniquement." Für die Zitate vgl. Josep Maria Montaner: „Matière et technique de la critique“ (1999), in: La critique architecturale. Questions - frontières - desseins, hg. v. Agnès Deboulet, Rainier Hoddé u. André Sauvage, Paris 2008, S. 123-136, hier: S. 134. 
schen Kontakt mit diesen Quellen, wohl aber einer intellektuellen Kommunikation mit deren Ge- und Inhalten gilt.

In den Schlussthesen zu seinem Beitrag „Der Dämon der Eingebung. Das Verstehbare und Nicht-Verstehbare beim Herstellen und Wahrnehmen von Kunst" hat Martin Zenck die hinter diesem zyklisch ablaufenden Prozess stehenden Faktoren herausgearbeitet:

Musik/Kunst kann nur innerhalb ihres Mediums durch die musikalische Aufführung, durch eine entsprechende Neu-Komposition/Transcription oder durch die Übermalung mimetisch verstanden werden (Modelle: Weberns Bearbeitung von Bach's Ricercar und Francis Bacons Übermalung von Velasquez). ${ }^{23}$

Das bedeutet, verknappt gesagt, dass Kunst auch immer wieder von anderer, früherer Kunst handelt, sich auf sie rückbezieht, auf sie zurückgreift, sich dort anlagert, sie damit aber auch überlagert, angreift und somit ein Stück weit verstellt. Damit werden zugleich die haptischen und mimetischen Qualitäten des Erkennens deutlich, denn im Zuge der eigenen Standortbestimmung des Künstlers, seinem Versuch, vorangegangene Kunst zu verstehen, sich mit ihr auseinanderzusetzen, rekurriert er nicht selten auf ein Verfahren, bei dem die Prozesse von Begreifen und Erfassen sowohl wörtlich als auch im übertragenen Sinn zu denken sind: Frühere Werke werden erfasst und ergriffen, an das zu Verstehende wird Hand gelegt, um es im einem re-kreativen Akt einerseits zu analysieren und weitestgehend zu durchschauen, es im Gefolge dieses Verstehens aber zugleich zu interpretieren, und das bedeutet auch: dem eigenen Verständnis gemäß umzugestalten, zu adaptieren und damit: zu überschreiben. So erhellend dies nun für Publikum und nachfolgende Künstler sein kann, so sehr mögen sie sich mit zunehmender Anzahl an gebotenen Verständnisvorschlägen, Interpretationen und Deutungen nach dem dahinter mehr und mehr verschwindenden Ursprungswerk sehnen und schließlich seine Präsenz „diesseits der Hermeneutik“ suchen. Doch indem sie es sodann im Neuvollzug des Verstehens wieder selbst begreifen, erfassen und damit überschreiben, arbeiten sie an der neuerlichen Entstehung eines Palimpsests mit, das der nachfolgenden Generation als Aufgabe hinterlassen wird.

Das hier verknappt und sehr theoretisch Formulierte soll im Folgenden anhand des Librettos zu der Oper Orphée-Roi exemplifiziert werden, das der französische Schriftsteller, Schiffsarzt und Ethnologe Victor Segalen (1878-1919) zwischen 1907 und 1915 zusammen mit dem Komponisten Claude Debussy (1862-1918) konzipierte und realisierte. Hierbei und indem Gumbrechts Modell einer Suche nach einem Präsenz ermöglichenden Standpunkt "diesseits der Hermeneutik“ als Denkfigur angewendet wird, kann zugleich deutlich gemacht werden, dass sich die in Gumbrechts Buch beschriebene Krisensituation schon zu Beginn des 20. Jahr-

$23 \mathrm{Vgl}$. auch seinen einleitenden Beitrag in diesem Band: „Auch das Übermalen, Überzeichnen und Überschreiben, das den ästhetischen Status des Nachmachens und Nachahmens übersteigt, fällt noch in ein Verfahren der mimetischen Praxis, die am Beginn und vielleicht auch am Ende jedes Verstehens steht.“ 
hunderts manifestierte, dort zwar nicht in didaktisch-philosophischer Weise, doch als Stoff für eine Oper und in deren Ästhetik artikulierte.

Da das Libretto Victor Segalens bislang noch nicht in deutscher Übersetzung vorliegt, ferner auch in seiner französischen Originalfassung nicht leicht zugänglich ist ${ }^{24}$ und daher wohl in jüngerer Zeit wieder in Vergessenheit zu fallen droht, ${ }^{25}$ soll zunächst eine kurze Inhaltsangabe der einzelnen Akte der Oper gegeben werden. Da die dort gegebene Interpretation des Orpheus-Mythos jedoch ungewöhnlich, geradezu gegen den Strich gebürstet, ausfällt, ist es unerlässlich, dieses Referat etwas detaillierter zu gestalten, da sonst das Wesentliche und Besondere der durch viele Abweichungen vom tradierten Mythos charakterisierten Erzählung nicht deutlich würde.

\section{Orphée-Roi}

\section{Prolog:}

„Nachdem alles Licht gelöscht wurde, ist hinter dem geschlossenen Vorhang in unerreichbarer Ferne klar, triumphierend (...) eine Stimme zu vernehmen " ${ }^{26}$ die in großen, wilden Sprüngen singt, begleitet von einer Lyra, deren Klang die Atempausen so füllt, dass keine Stille aufkommt.

Der Vorhang öffnet sich auf eine im frühen Morgenlicht daliegende Berglandschaft: zwei Gestalten, ein Priester und ein Krieger, treten in Tierfellen auf und

24 Es liegt zum einen in der selten verfügbaren, da in geringer Auflage gedruckten Originalveröffentlichung vor: Le Théâtre d'Art: Orphée-Roi par Victor Segalen. Paris 1921; zum anderen haben Segalens Tochter, Annie Joly-Segalen, und André Schaeffner, den Text erneut in dem von ihnen herausgegebenen Sammelband Segalen et Debussy, Monaco 1961, S. 219-341, aufgenommen. Im Folgenden wird nach dieser Ausgabe zitiert und übersetzt, die zudem den Vorteil hat, dass sie die ursprünglichen Fassungen Segalens und die Korrekturen Debussys daran mit abdruckt - ein Vorteil, auf den bei der erneuten Ausgabe im Rahmen der von Henry Bouillier verantworteten, zweibändigen Oeuvres complètes (Paris 1995, Vol. 1, S. 667-702) wieder verzichtet werden musste; Bouillier druckt ebd., S. 617-666, auch die bereits bei Joly-Segalen wiedergegebenen Gespräche und Briefe Debussys und Segalens über den Orphée-Roi ab. Die drei Originalmanuskripte befinden sich in der Bibliothèque Nationale de France, Paris (BNF, Manuscrits, N.a. fr. 25798 u. 25799) sowie der Bibliothèque Municipale von Brest (Ms 55).

25 Nachdem Eva Kushner: Le mythe d'Orphée dans la littérature française contemporaine, Paris 1961, Segalens Libretto bereits besprochen hatte, widmete Jean-Louis Bédouin dem Projekt ein Kapitel in seiner Monographie Victor Segalen, Paris 1963, S. 47-55. Beide Texte wurden von Rollo Meyers: „The opera that never was: Debussy's collaboration with Victor Segalen in the preparation of Orphée", in: The Musical Quarterly, Oktober 1978, Vol. LXIV, No. 4, S. 495-506, offenbar nicht wahrgenommen, denn er behauptet (ungeachtet der ausführlichen und über seine eigenen Darlegungen weit hinausreichenden Diskussion von Kushner) S. 495, das Libretto sei nach wie vor "worth a fuller analysis than has hitherto (to my knowledge) been attempted". In der erweiterten Neuauflage seiner 1961 erstmals (als Doktorarbeit) veröffentlichten Biographie Victor Segalen, Paris 1986, bespricht Henry Bouillier in dem Kapitel „Segalen et la musique“ auch den OrphéeRoi. Nichtsdestotrotz lässt Wilfried Mellers in seinem Buch The masks of Orpheus: Seven stages in the story of European music, Manchester 1987, Segalens Libretto schon wieder unerwähnt.

26 Joly-Segalen: Segalen et Debussy, S. 225. 
versuchen vergeblich, den unsichtbaren Sänger einzuholen. Sie stoßen dabei auf den alten Kitharoden, der sie zum Schweigen anhält, da er der Stimme lauschen möchte und befürchtet, der Gesang könnte unterbrochen werden: „(...) ich kann nicht mehr weiterleben, außer in der lebendigen Luft seiner Stimme “. ${ }^{27}$ Priester und Krieger überreden den Alten, sie zu dem Sänger zu führen: Von einem Orakel haben sie den Auftrag erhalten, ihn, der durch seinen Gesang über Natur und Tiere herrscht, zum König über die Menschen zu krönen.

\section{Das Bühnenbild verwandelt sich zum}

\section{Akt, 1. Szene:}

In der Mitte der Berg-Muschel steht der Sänger, in hymnischem Gesang erstrahlend. Der Priester und der Krieger sprechen ihn als „König von Thrakien“ und „Oberhaupt der Hundert Krieger“ an - der Sänger unterbricht seinen Gesang: Zum ersten Mal seit Beginn der Oper tritt Stille ein. Doch er scheint sie nicht zu verstehen oder gar zu hören - er schweigt und wendet sich schließlich zum Gehen. Der alte Kitharode versucht, ihn zurückzuhalten, indem er die letzten Klänge des Gesangs auf seiner Kithara wiederholt - der Sänger verharrt und antwortet nun auf die Frage nach seinem Namen: „Orpheus“ - „(..) der Name donnert durch die Berge “, ${ }^{28}$ der Sänger verschwindet. Krieger und Priester erinnern sich an die auf Orpheus bezogenen Worte des Orakels: „Der, (...) welcher mit all seinen Ohren sieht und mit all seinen Augen den Blick hört. "29 Sie versuchen, Orpheus einzuholen, doch der Kitharode hält sie zurück und erklärt ihnen, dass nur ein einziger Mensch ihn noch einholen könne: „Eurydike! Meine Tochter“ ${ }^{30}$ die er hinter Orpheus herschickt.

Ein sinfonisches Zwischenspiel bei geschlossenem Vorhang lässt den Hörer den Lauf der Eurydike durch das Gebirge, hinter Orpheus her, mitverfolgen.

Die 2. Szene in einer sich tief nach hinten erstreckenden Höhle zeigt „Orpheus, alleine, wie ein Wilder hinter Laubwerk zusammengekauert, keuchend “ $:{ }^{31}$ Er beklagt, dass die Menschen ihn gefunden haben, deren lärmende Worte er flieht. Er sehnt sich nach einer Stimme, die auf seinen Gesang adäquat und würdig zu antworten vermag - aber bislang antworten nur Tiere und Felsen. Er hört, wie sich ihm jemand nähert: „(...) keine Menschen...Das sind nicht meine vertrauten Tiere (...) Etwas Unbekanntes, Unerhörtes näher sich mir..." ${ }^{32}$ Es ist Eurydike - sie versucht, mit ihm zu sprechen, erwähnt seine Lyra, die er verbotenerweise mit 12 Saiten bespannt hat, und die über ihn kursierenden Gerüchte (dass er vom Himmel gefallen sei). Als sie versucht, ihn zu ihrem Vater zurückzuführen, gesteht er, dass er ihre mit Gesang begabte Stimme liebe. Eurydike führt ihn daraufhin zu den Menschen zurück - der Vorhang fällt.

27 Ebd., S. 233.

28 Ebd., S. 242.

29 Ebd., S. 243.

30 Ebd., S. 244.

31 Ebd., S. 245.

32 Ebd., S. 246. 


\section{Akt, 1. Szene:}

Aus dem tiefen und dumpfen Rumoren einer nachts an Wald und Fluss stehenden, jedoch noch unsichtbaren Menge lösen sich drei Stimmen: der Priester, der Krieger und die Priesterin der Mänaden, die über Orpheus, seine Fremdheit und darüber sprechen, dass er die Menschen befriede und sich Eurydike zur Frau genommen habe. Während der Krieger mit Orpheus als König unzufrieden ist (ihm zufolge kein guter Kämpfer, sondern vielmehr ein sich nur mit Gesang befassender Feigling), klagt der Priester den Sänger an, die Gesetze verletzt zu haben, indem er die geheiligte Zahl der Lyra-Saiten erhöht und ferner unwürdige, neue Gesänge eingeführt habe. Orpheus selbst tritt in königlichen Gewändern auf, wird von dem Krieger provoziert, der Unterstützung von der aus dem Wald heraustretenden Menge erhält. Als er sich jedoch dem Sänger nähert, wird er von den Strahlen des orphischen Gesangs getroffen - wie gleichgültig geht Orpheus davon, während die Menge und der Krieger verblüfft zurückbleiben. Der Vorhang schließt sich - die Stimmen entfernen sich bis zur 2. Szene am Flussufer: Orpheus scheint zu schlafen, Eurydike sucht ihn auf, klagt über die von ihm geduldeten Spottreden sowie über seine Dis$\operatorname{tanz}$ zu ihr. Der Sänger erwacht, spricht von ihrer fernen, unerwarteten Stimme, wünscht sich, dass sie ihm antworte, dass auch sie ihm zuhöre, mit ihm lausche „bis auf den Grund der Welt. “33 Er vernimmt einen seltsamen, unmenschlichen Gesang, doch Eurydike hört nur die Geräusche der Natur. Er fühlt sich daher einsam und beklagt, dass ihr Körper noch immer an die Erde gefesselt sei, während er tatsächlich längst in den Wolken des Klangs schwebe: Er verfällt in eine Ekstase, aus der ihn Eurydike verzweifelt zurückzuholen versucht: Sie will nicht von seinem Traum ausgeschlossen sein. Mit ihrem ganzen Körper wirft sie sich auf Orpheus, umschließt, liebkost ihn: „Ein Schrei...Eurydike fährt zurück...(...) jegliche Musik verstummt. Lang anhaltende Stille". ${ }^{34}$ Sie entschuldigt sich - sie hat nicht nur eine Saite an der Lyra des Orpheus zerrissen (ohne sie auch nur berührt zu haben), sondern die Welt ist für den Sänger nach ihrer körperlichen Berührung auch mit einem Male verstummt. Orpheus ergreift die Lyra, entdeckt die "tote Saite“, ${ }^{35}$ beklagt seine Einsamkeit und geht davon. Eurydike bricht in Schluchzen aus - der Vorhang fällt „,brutal“ “ ${ }^{36}$

In Form eines sinfonischen Zwischenspiels hört man das die ganze Nacht hindurch andauernde Weinen der Eurydike. Der Vorhang hebt sich - nun behut$\operatorname{sam}^{37}$ - zur 3. Szene: Der alte Kitharode findet seine Tochter am nächsten Morgen am Fluss vor - sie möchte getröstet werden und berichtet von den Ereignissen der vergangenen Nacht. Doch der Vater wirft ihr vor, sich Orpheus gegenüber, der anders als jeder Mensch sei, gewöhnlich und vulgär verhalten zu haben. Eurydike jedoch ist in ihrem Stolz gekränkt und will einen Mann, ein Familienoberhaupt, das sich um sie sorgt und bemüht. Der Kitharode erzählt ihr von Orpheus: Dass er

33 Ebd., S. 268.

34 Ebd., S. 272.

35 Ebd., S. 275.

36 Ebd., S. 275: „(...) brutalement “.

37 Ebd., S. 275: „(...) très doucement”. 
weder Mensch noch Gott, alterslos sei, und welche Ehre es bedeute, dass er sich Eurydike zur Frau gewählt habe. Er überzeugt sie - getröstet und erleichtert empfindet sie nun Verlangen nach Orpheus, zugleich jedoch auch Angst vor dem Tod.

Der Vorhang grenzt diese Szene vom III. Akt ab, der nur in einer einzigen Szene besteht, die an einem Mittag an "Säulenhalle und Meer" spielt - große Stille herrscht. Orpheus lehnt an einer Säule, Eurydike nähert sich ihm, „gekleidet wie für eine Hochzeit oder ein Opfer oder eine Gabe. ${ }^{\text {38 }}$ Sie fühlt sich schuldig an seinem Schweigen und überlegt nun, wie sie sich ihm dieses Mal auf würdige Weise nähern kann. Der Sänger beklagt (,mit fast menschlicher Stimme“) $)^{39}$ den Verlust Eurydikes, die er gar nicht wahrnimmt, selbst, als sie ihm gegenübersteht, ihm zu widersprechen versucht: Sie sei wieder gefunden, ihm ganz nah. Orpheus spricht von der Macht, die sie - wie niemand sonst - über ihn habe; er weint - Eurydike erkennt, dass er menschliche Regungen hat, sich hier auf ihre Ebene herab begibt. Sie bittet ihn um Entschuldigung und ruft ihn dazu auf, sich von ihr zu befreien, wieder Herrscher zu sein, die von ihr zuvor mit Eifersucht betrachtete Lyra wieder aufzunehmen, als deren Sklavin sie sich nun sieht, und so die Stille zu vertreiben. Nun erkennt der Sänger sie; Eurydike fordert ihn auf, die Macht seines Gesangs unumschränkt auszuüben: Unter dem Klang ihrer sich vereinigenden Stimmen beginnt die sie umgebende Welt zu antworten - alles - der Palast, die Erde, die Luft - alles füllt sich mit Musik. Eurydike bittet nun darum, ein Gesang des Orpheus werden zu dürfen - sie möchte ganz in ihm aufgehen, sich ganz in ihm auflösen: „Sei ohne Gnade: vollende dein Werk an mir! “40 Orpheus zögert zunächst noch, doch dann erkennt er: „Du willst... in deinem Fleisch erklingen! Du willst....dich aus dem Fleisch befreien! " ${ }^{41}$ Und er stimmt seinen Gesang an, unter dessen Macht sich Sonne, Meer und Säulenhalle auflösen: „Die Welt ist klingend! (...) Das Werk ist vollendet. Das Werk ist schön. “42 Eurydike wird zu einem Gesang, zum Echo des Orpheus - sie sinkt zu Boden - umschlungen von Musik hebt sich alles in Klang auf. ${ }^{43}$

Der Vorhang hebt sich wieder zum $I V$. Akt, 1. Szene im "unterirdischen Tempel und der Höhle“: Ein Schrei - der Kitharode stürmt die Treppe hinab, betritt den Tempel und verkündet den Tod seiner Tochter - hier sucht er eine Begräbnisstätte für sie. Der Priester, der Krieger und die Mänade kommen aus dem Tempelinneren hervor und befragen ihn nach den Umständen von Eurydikes Tod. Sie klagen Orpheus an, sie getötet zu haben, da er sie nicht mehr geliebt habe: Er habe nicht über ihren Tod geweint und versäumt, die üblichen Grabgesänge anzustimmen. Der Kitharode verteidigt demgegenüber den Sänger, der nichts von Eurydikes Tod zu wissen scheine, sie vielmehr suche. Als Orpheus naht, beschließt die Mänade, den Sänger in die Höhle zu locken, um ihn dort zur Strafe zu töten. Giftige Dämpfe wallen auf, verdecken die Bühne, die sich in der 2 . Szene zu einem unbeschreibba-

38 Ebd., S. 284.

39 Ebd.

40 Ebd., S. 299.

41 Ebd., S. 300.

42 Ebd., S. 303f.

43 Ebd., S. 304: „Tout s'exalte dans la sonorité.“ 
ren Ort verwandelt: eine „schleimige Höhle“ wie aus "giftigem Fruchtfleisch“ ${ }^{4} 4$ Orpheus gebärdet sich wie rasend: „Tiefer, tiefer! Bis in den unreinen Bauch der Erde hinab... ", ${ }^{45}$ singt er, während er nach Eurydike sucht, von der er weiß, dass sie nicht tot sein kann. Eine Form quillt ihm entgegen - Orpheus glaubt in ihr, trotz der falsch klingenden Stimme, Eurydike wieder zu erkennen; er will sie zurückholen in den klingenden Palast. Die Form preist sich glücklich, dass er hier ist: Sie werde ihn hier behalten, er werde ihr nicht mehr entkommen - sie gibt sich als die Mänade zu erkennen. Orpheus erschickt - noch immer glaubt er, Eurydike vor sich zu haben, welche sich aus dem Reich des Geistes, der Klänge wieder dem Fleisch, dem Schmutz zugewendet habe. Er versucht, ihr zu helfen, will singen, aber die Lyra bleibt stumm. Die Mänade triumphiert - sie glaubt, er, den sie liebt und begehrt, müsse in ihren Armen sterben: „Ich bin hier die Königin. Ich bin trunken. Ich, die Priesterin, habe mir meinen Gott gepackt! “46 Als sie versucht, ihn zu ergreifen, zu umarmen, erkennt er, dass sie nicht Eurydike sein kann; er erhebt die Lyra - „Ah! Die Frau möge sterben! Lyra, mach mir den Weg frei! Meinen Weg! “47 - und zerreißt ihre Saiten, deren Klang die Höhle wie eine Frucht aufplatzen lässt. Er verlässt den Ort, dessen Trümmer die Mänade unter sich zerquetschen.

Als „Interlude“ schildert eine ausführliche Tondichtung, wie Orpheus zu den Menschen zurückkehrt, die dem Kampf in der Höhle gelauscht haben: Sie feiern ihn, „der die Höhle besiegt hat, der von einem Ort zurückgekehrt ist, von dem noch kein Mensch jemals menschlich zurückgekehrt ist “. ${ }^{48}$ Der Sänger verlässt jedoch bald ihre von Neid und Lob gleichermaßen erfüllte Feier und kehrt zu dem klingenden Palast zurück, der noch immer vom Tod der Eurydike erbebt. ${ }^{49}$

„Der Vorhang hebt sich ein letztes Mal ${ }^{“ 50}$ zum V. Akt (Epilog), mit dem zum Schauplatz des Prologs und des ersten Aktes zurückgekehrt wird: Berglandschaft.

Orpheus sitzt singend da; der Kitharode kommt herbei und berichtet von den Menschen: dass sie sich gegenseitig für Orpheus ermorden, da die einen ihn für einen Betrüger, die anderen ihn für einen wiederauferstandenen Gott halten, dass sie Fetzen seiner Tunika als Reliquien sammeln, seine Gesänge nachahmen. Sie kommen auf Eurydike zu sprechen - als Orpheus ihren Namen ausspricht, wird er von Myriaden murmelnder Stimmen in der Natur wiederholt; der Kitharode begreift, dass sie lebt, unsterblich geworden ist. Eigentlich aber ist er gekommen, um Orpheus vor den herandrängenden Mänaden zu warnen, die sich unter Gezischel nähern, um den Tod ihrer Priesterin zu rächen. Als der Sänger trotzdem in Ruhe verharrt, fleht ihn der Kitharode an: „Aber deine Stimme! Sie werden auch sie zerreißen... Sie ebenfalls erwürgen...Deine Stimme wird ebenfalls sterben und es wird nichts bleiben als Stille... Hab Mitleid mit denen, die kommen werden, mit

44 Ebd., S. 313.

45 Ebd., S. 314.

46 Ebd., S. 325.

47 Ebd., S. 326.

48 Ebd., S. 327.

49 Ebd.: „(...) encore vibrant de la Mort d'Eurydice. “

50 Ebd., S. 329. 
deinen Untertanen, deinen Söhnen in einer klingenden Welt, ${ }^{51}$ Orpheus, König Orpheus! ${ }^{\text {"52 }}$ Er wirft sich in Anbetung vor ihm nieder - Orpheus wappnet sich zum Kampf, hält die Lyra wie einen Schild vor das Gesicht. Die Mänaden stürzen hervor, packen Orpheus, reißen ihn mit sich fort - der Kitharode versucht, ihn zu schützen, wird jedoch beiseite geschleudert: „Eine schwarze Welle verschluckt alles... eine letzte Stille bricht an. ${ }^{\text {"53 }}$ Der Kitharode entdeckt die am Boden liegende Lyra und ergreift sie - er stirbt jedoch in dem Moment, in dem er sie berührt. Langsam erhebt sich die Lyra, schwebt, fährt empor - die Stimme des Orpheus erklingt: „in ihrer Epiphanie herrschend über die stumme Erde, die Wälder und Felsen, die Spiele, die Liebschaften und Schreie, aufsteigend, triumphal, - sie, die im Höchsten der singenden Himmel regiert. " 54

Bereits angesichts einer solchen Zusammenfassung dürfte deutlich geworden sein, dass zwischen Segalens und Debussys Orphée-Roi und der herkömmlichen Orpheus-Sage nur noch in Form einzelner Figuren (Orpheus, Eurydike), Schauplätze (die Unterwelt), Handlungsmomente („Tod“ der Eurydike, der Gang des Orpheus in die Unterwelt, um Eurydike zu suchen) und Motive (Tiere und Felsen lauschen der Musik des Sängers - bei Segalen allerdings bereits schon vor dem Tod der Eurydike) Ähnlichkeiten bestehen, während diese ansonsten jedoch vollkommen neu angeordnet, gewichtet und motiviert werden. Die Gründe für diese Verschiebungen werden üblicherweise - und wie gleich zu sehen sein wird: zurecht - in den Ausgangsbedingungen und Entstehungskontexten des Librettos gesucht; dennoch scheint es so, als ob mit einer solchen Untersuchung der Lage Claude Debussys, der Interessen Segalens, der von beiden zunächst in den Blick genommenen Grundidee sowie der Dynamik der weiteren Zusammenarbeit gleichsam nur die Symptome, nicht jedoch die tatsächlichen Triebkräfte für eine derartige Umgestaltung des Orpheus-Stoffes in den Blick genommen würden. Ihnen wird daher - nach einer Sichtung der oben genannten Faktoren - abschließend nachgespürt.

\section{Ausgangsbedingungen und Entstehungskontexte}

\section{Claude Debussy}

Nach der Komposition und tumultuösen Uraufführung ${ }^{55}$ seiner Oper Pelléas et Melisande am 27. April 1902, an der Debussy seit 1893 gearbeitet hatte, unternahm der Komponist wiederholt Versuche zu einer neuen Oper, die jedoch entwe-

51 Ebd., S. 338: „(...) dans un monde sonore.“

52 Ebd.

53 Ebd., S. 340.

54 Ebd., S. 341.

55 Vgl. z.B. Jean Barraqué: Debussy. Reinbek bei Hamburg 1964, S. 107; ihm zufolge nahmen u.a. die Handgreiflichkeiten ein solches Ausmaß an, dass die Polizei einschreiten musste. 
der alle unvollendet oder sogar im Stadium der bloßen Projektierung liegen blieben. Er kommentierte dies 1909 selbst sogar einmal in spöttischem Ton:

Ich habe dieses eigentümliche Bedürfnis, Werke unvollendet zu hinterlassen - (ein Bedürfnis), welches die entgegen gesetzten „Bedürfnisse“ meines Verlegers nicht im mindesten befriedigt. ${ }^{56}$

Damit deutet Debussy einen möglichen Hinderungsgrund bei der Ausarbeitung und Fertigstellung einer weiteren Oper an, denn sein Verleger Jacques Durand (dem der Komponist eine größere Summe Geld schuldete) scheint ihn gedrängt zu haben, zeitlich weniger aufwändige, schneller verfügbare Werke zu schreiben. ${ }^{57}$ Darüber hinaus erwies sich Debussy jedoch seine ganze Laufbahn hindurch als ein Kopf, der sich schnell für neue Pläne begeistern ließ, deren Ausarbeitung ihn dann jedoch eher ermüdete. ${ }^{58}$ Doch nach dem Pelléas hatte der Komponist auch und vor allem das Problem, dass er weder einen idealen Textdichter, noch eine geeignete Vorlage zu finden vermochte - Künstler wie Louis Laloy, Paul-Jean Toulet und René Peter (welche - wie er selbst und dann später auch Segalen - interessanterweise eine starke Affinität zu fernöstlichen Kulturen aufwiesen) waren in seinen Augen zu sehr Literaten, weshalb ihre häufig recht komplexen Libretti von ihm dann auch als zu „literarisch“ und zu wenig „lyrisch“ eingeschätzt wurden. ${ }^{59}$ Dies schlägt sich auch in dem Umstand nieder, dass Debussy mehr Musik für Ballette schrieb, wo ihm als Komponisten größere Freiheit im Umgang mit der textlichen Vorlage zugestanden war. Zugleich lässt sich bei ihm in seinen späteren Jahren eine eindeutige Bevorzugung von wortungebundener, ja: teilweise sogar absoluter Musik beobachten - so schrieb Debussy 1915 in einem Brief an den Dirigenten Bernardino Molinari:

56 Debussy in einem Brief an Gabriel Mourey vom 6. Januar 1909, übersetzt nach Robert Orledge: Debussy and the theatre. Cambridge 1982, S. 257.

57 Orledge: Debussy and the theatre, S. 296-298, weist darüber hinaus darauf hin, dass Debussy wohl später auch von seiner zweiten Frau Emma zu zwar lukrativen, doch zeitintensiven Unternehmungen wie Dirigententourneen angehalten worden sei.

58 Orledge: Debussy and the theatre, S. 298, weist in diesem Zusammenhang darauf hin, dass nicht wenige seiner Werke von Schülern wie z.B. André Caplet instrumentiert wurden.

59 Auch mit Segalen hatte Debussy dieses Problem - aus den Gesprächsprotokollen Segalens geht immer wieder hervor, dass Debussy sich an Passagen des Libretto-Entwurfs störte, die seiner Meinung nach zu wenig lyrisch waren: vgl. z.B. Protokoll vom 6. Mai 1908 (Joly-Segalen: Segalen et Debussy, S. 96) oder den Brief Debussys an Segalen vom 27. August 1908 (Joly-Segalen: Segalen et Debussy, S. 101), wo er sogar einen "literarischen" von einem "lyrischen" Satzrhythmus unterscheidet. In einem Brief vom 28. September 1908 äußert der Autor dem Komponisten gegenüber die Hoffnung, dass er mit Debussys Unterstützung lernen werde, „lyrisme“ in literarischer und musikalischer Hinsicht voneinander zu unterscheiden; vgl. dazu Joly-Segalen: Segalen et Debussy, S. 103 sowie Henry Bouillier (Hg.): Victor Segalen - Correspondance, 2 Vols., Paris 2004, Vol. I, S. 789 . 
Welche Schönheit liegt doch in der Musik selbst, welche keinen vorgeschriebenen Zweck hat. (...) Für viele Leute werden die (...) Sonaten, die ich schreibe, nicht die Wichtigkeit einer Oper haben. (...) Aber es schien mir, dass sie der Sache der Musik besser dienen würden. ${ }^{60}$

Dennoch hegte der Komponist gerade in den Jahren nach der Uraufführung des Pélleas in Bezug auf das Musiktheater große und ehrgeizige Pläne: Eine neue Art von lyrischer Kunst sollte geschaffen werden, um die überkommenen „dahinsiechenden Opern-Ballette "61 zu ersetzen. Dabei fürchtete Debussy jedoch einen direkten Vergleich mit der eigenen Erstlingsoper, da er bestrebt war, beständig Neues zu schaffen, u.a. auch, um keinen "Debussysmus" aufkommen zu lassen. ${ }^{62}$

Insofern ist es verständlich, dass er sich - nachdem er im Pélleas bereits eine märchenhaft-mittelalterliche Welt gestaltet hatte - später von der Idee einer zu einer ganz anderen Zeit und in einer ganz anderen Kultur spielenden Orpheus-Oper begeistern ließ. Dies umso mehr, als er selbst einmal den Nutzen umrissen hatte, der aus dem Versuch gezogen werden könne, sich den „theatralischen Ideen der alten Griechen" zuzuwenden:

Lasst uns die Tragödie wieder entdecken und ihre primitive musikalische Begleitung mit den gewaltigen Mitteln des modernen Orchesters und eines unbegrenzten Chores verknüpfen! ${ }^{33}$

Eine ganz ähnliche Vorstellung vom Zusammenwirken archaischer Primitivität und modernem musikalischen Fortschritt sollte er in einem 1907 auf seine eigene Anregung und Vermittlung publizierten Aufsatz Victor Segalens über die Musik der Ureinwohner Tahitis, der Maori, begegnen, ${ }^{64}$ und so nimmt es nicht wunder, dass Debussy sich für Segalen als seinen Textdichter entschied und ihm den Vorschlag einer

60 In einem Brief vom 5. Oktober 1915, übersetzt nach Orledge: Debussy and the theatre, S. 299.

61 Ebd., S. 292.

62 Ebd., S. 296-299. Vgl. ferner den Ausspruch Debussys, den Segalen in einem Gesprächsprotokoll festhielt, das er nach einem Arbeitstreffen am 8. Oktober 1907 notierte (hier übersetzt nach JolySegalen: Segalen et Debussy, S. 71): „Ich habe den Pelléas“ geschaffen. Na gut - und was weiter? Pelléas! Dieser Herr da langweilt mich. Ich frage mich jetzt, ob ich nicht dabei bin, ihn unendlich zu wiederholen. Und das will ich gerade nicht. Es würde mich einschläfern, ihn wieder vor vorne zu beginnen oder einen klanglichen Zwilling dazu zu schaffen. Es muss weitergehen. Andernfalls würde ich lieber ... Landwirtschaft betreiben."

63 Orledge: Debussy and the theatre, S. 289. Zum historischen Kontext von Debussys Vorhaben (der Rekonstruktion der antiken Tragödie in Form der Oper in der Frühen Neuzeit und der Notwendigkeit einer Lösung der damit einhergehenden formalen Probleme im 19. Jahrhundert) vgl. Henry Keazor: „,cosa mezzana'/,chanter sans paroles': ,Euridice‘ (Jacopo Peri, Ottavio Rinuccini) e ,Orphée-Roi" (Claude Debussy, Victor Segalen)“, in: Musica e arti figurative: Rinascimento e Novecento, hg. v. Mario Ruffini u. Gerhard Wolf, Venedig 2008, S. 199-211.

64 Victor Segalen (unter dem Pseudonym „Max-Anély“): „Voix mortes: musiques maori“, in: Le Mercure Musical, 15. Oktober 1907, S. 1005-1027, wiederabgedruckt bei Joly-Segalen: Segalen et Debussy, S. 153-183. Bezüglich dieser Bezeichnung „Maori“, mit der heute die Ureinwohner Neuseelands belegt werden, vgl. Segalen: Ästhetik, S. 22: „Wenn hier wie auch im folgenden Text von den Maori die Rede ist, sind damit immer die Angehörigen der alten polynesischen Kultur auf Tahiti gemeint.“ Zum Pseudonym „Max-Anély“ vgl. Kushner: Le mythe d’Orphée, S. 139. 
Orpheus-Oper unterbreitete - das Sujet, so Debussy 1907 in einem Gespräch mit Segalen, sei nicht nur "extrêmement musical“, sondern biete ihm auch die Möglichkeit, „Dinge zu verwirklichen, die ich anders, mit einem anderen Stoff nicht verwirklichen könnte. "65 "Dies wäre somit mein musikalisches Testament" ${ }^{66}$

Dies zu formulieren und zu hinterlassen wäre ihm wohl umso wichtiger gewesen, als er sich zeitgleich zu seinem Engagement für den Orphée-Roi auch mit der Idee zu einer "Tristan“-Oper trug - beides Projekte, mit denen er offenbar Korrektive zum „Musikdrama (...), diesem Gluck-Wagner-Import, der unserem Genie so sehr entgegensteht ${ }^{\text {“67 }}$ vorlegen wollte. Tatsächlich äußerte der Komponist auch seine Absicht, mit seinen Opern zum einen „Tristan seinen legendären Charakter wiederherzustellen, der durch Wagner und diese zweifelhafte Metaphysik so sehr entstellt " ${ }^{68}$ worden sei, zum anderen aber Glucks Interpretation des Orpheus-Stoffes zu korrigieren, in der „nichts anderes als die anekdotische und weinerliche Seite" desselben herausgearbeitet worden sei, ${ }^{69}$ während das eigentlich Wesentliche unthematisiert geblieben sei: „(...) weshalb Orpheus der Erste und Erhabendste der Unverstandenen" gewesen sei. ${ }^{70}$

\section{Victor Segalen}

Sie können tatsächlich kaum glauben, wie entscheidend vielleicht diese Verwirklichung eines sehr alten Wunsches für mich ist. Ihnen, dem Künstler, der mir soviel schöne und große Freude bereitet hat, etwas von dem zu geben, was ich ihm schulde, in Form künstlerischen Materials, den Möglichkeiten, weiter zu schaffen, ${ }^{71}$

schrieb Segalen am 30. April 1906, fünf Tage, nachdem er sich Debussy zum ersten Mal vorgestellt hat, an den von ihm so bewunderten Komponisten. Über diese Freude, das ästhetische Erlebnis hinaus aber verdankte ihm der durchaus musikalisch begabte Schriftsteller seiner Ansicht nach noch weit mehr, denn er bezeichnet

65 So Debussy einem Gesprächsprotokoll zufolge, das Segalen nach einem Arbeitstreffen am 10. Oktober 1907 notierte - es wird hier übersetzt nach Joly-Segalen: Segalen et Debussy, S. 80.

66 Ebd.

67 Claude Debussy: Monsieur Croche - Sämtliche Schriften und Interviews, hg. v. François Lesure. Stuttgart 1982, S. 267. Bezüglich der engen, geradezu genealogischen Verbindung, die Debussy zwischen Gluck und Wagner sah vgl. ebd., S. 289: „Gluck und seine Adepten, die von fern das Wagnertum vorbereiteten“ sowie S. 104 im „Offenen Brief an Gluck“: „(...) bei Ihnen steht die Wiege der wagnerischen Formeln und das ist unerträglich."

68 Brief Debussys an Victor Segalen vom 26. Juli 1907, übersetzt nach Joly-Segalen: Segalen et Debussy, S. 62.

69 Brief Debussys an Victor Segalen vom 26. August 1907, übersetzt nach Joly-Segalen: Segalen et Debussy, S. 67. Im Vorwort zum Libretto zitiert Segalen (Joly-Segalen: Segalen et Debussy, S. 220) diese Passage ausdrücklich.

70 Joly-Segalen: Segalen et Debussy, S. 67. Auf diese Idee war Debussy nach der Lektüre von Segalens Novelle „Dans un monde sonore" gekommen - zu dieser siehe ausführlicher unten.

71 Übersetzt nach Joly-Segalen: Segalen et Debussy, S. 53. 
ihn als „denjenigen, der mich zum Hören gebracht hat “ ${ }^{72}$ Jedoch auch auf dem Gebiet der Literatur ist Debussy für ihn „le Maître“" ${ }^{73}$ von dem er - durch die beständigen Korrekturen des Komponisten am Libretto - viel gelernt habe. ${ }^{74}$

Abgesehen aber von Dankbarkeit, Verehrung und freundschaftlicher Verbundenheit sah Segalen den Orphée-Roi auch als eine entscheidende Station innerhalb seines eigenen Werkes an. So war die Oper zum einen als Teil einer geplanten Triologie "Cycle des héros" vorgesehen, welche Dramen bzw. Opern über Siddharta, Janus ${ }^{75}$ und Orpheus umfassen sollte, ${ }^{76}$ zum anderen sah der Schriftsteller hier die Möglichkeit gegeben, auf poetische Weise sein Konzept des „Exotismus“ zu veranschaulichen, wie er es theoretisch ab 1904 in seinen „Notes sur l'exotisme“ zu einem geplanten Buch skizziert hatte. ${ }^{77}$

Und es sind eben die Schriften Segalens der Jahre zwischen 1904 und 1907, die sozusagen als „Vorhallen“ auf dem Weg zum Gedankengebäude des Orphée-Roi durchschritten werden müssen, um ein adäquates Verständnis desselben zu ermöglichen. Die vier wesentlichen Werke Segalens seien hier daher kurz in ihren wesentlichen Zügen umrissen.

\section{1. „Notes sur l'exotisme“}

Wie oben schon angedeutet, handelt es sich hierbei nicht um ein ausformuliertes Buch, sondern um ein Konvolut an Notizen, Entwürfen und Aufzeichnungen, an denen Segalen bis 1918 weiter arbeitete. Obgleich nie zu einem geschlossenen Text zusammengeführt, lässt sich seine Exotismus-Theorie anhand dieser Fragmente dennoch präzise rekonstruieren. Segalen will seinen Exotismus-Begriff dabei deutlich von jenen abgedroschenen Assoziationen unterschieden wissen, die gewöhnlich mit diesem Wort aufkommen, indem er betont, dass in dem Buch „trotz seines exotischen Titels (...) nicht die Rede von Tropen und Palmen, von Kolonien oder Negerseelen, (...) rauschenden Wogen und Gerüchen, nicht von Eingeborenenaufständen, vom Nichts oder vom Tod, nicht von farbigen Tränen, gelben Gedanken oder Absonderlichkeiten “ sei - „und von keiner der Ungereimtheiten, die das Wort ,Exotismus' in seiner üblichen Bedeutung enthält. ${ }^{\text {"78 }}$ Vielmehr verstehe er unter Exotismus „nur das eine, wenn auch unendlich Große: unser Gefühl des

72 In einem Brief vom 11. März 1916 an Jean Lartigue (übersetzt nach Joly-Segalen, S. 140; vgl. auch Bouillier-Segalen: Correspondance, Vol. II, S. 737f.); Segalen teilt hier die Nachricht vom Tode Debussys mit.

73 So im Gesprächsprotokoll vom 6. Mai 1908: Joly-Segalen: Segalen et Debussy, S. 96.

74 Vgl. z.B. Segalens Brief an Jules de Gaultier vom 28. Dezember 1908 (Joly-Segalen: Segalen et Debussy, S. 110).

75 Mit "Janus" ist der (unausgeführte) Plan zu einem Drama über den „doppelgesichtigen “ Dichter Arthur Rimbaud gemeint; vgl. Segalens Studie „Le double Rimbaud“ von 1907, in der die letzten Lebensjahre des Dichters besprochen und nach den Gründen und Konsequenzen seines zwiespältigen Lebens geforscht wird..

76 So Segalen in einem Brief an seine Frau vom 12. Juli 1909; vgl. auszugsweise Joly-Segalen: Segalen et Debussy, S. 112, sowie vollständig Bouillier-Segalen: Correspondance, Vol. I, S. 915-917.

77 Dann postum 1978 publiziert als „Essai sur l'exotisme“ (dt.: „Die Ästhetik des Diversen“).

78 Segalen: Ästhetik, S. 80. 
Diversen ", 79 mithin also eine Selbstwahrnehmung, die durch die Empfindung der Alterität, der Unterscheidung von anderen und anderem gesteigert, verfeinert und erweitert wird: „(...) der Begriff des Anders-Seins, die Wahrnehmung des Diversen, das Wissen, daß etwas nicht das eigene Ich ist", und er leitet aus diesem Bewusstsein auch die Fähigkeit ab, „anders aufzufassen " ${ }^{80} \mathrm{Im}$ Umkehrschluss folgt daraus, dass ,nur diejenigen, die eine starke Individualität besitzen, (...) den Unterschied fühlen“ ${ }^{81}$ "Das Gefühl des Exotismus und des Individualismus ergänzen sich $^{\text {" }}{ }^{82}$ und unsere Persönlichkeit wird durch die Begegnung mit dem Fremden, dem Nicht-Ich, „um das ganze Universum bereichert. " ${ }^{\text {"3 }}$ Dieser Zugewinn ereignet sich jedoch nur, wenn keinerlei Anpassung meinerseits an den anderen, oder umgekehrt, stattfindet, auch nicht in Form eines wechselseitigen Verständnisses. Voraussetzung ist vielmehr gerade die „scharfe, unmittelbare Wahrnehmung einer ewigen Unverständlichkeit “ ${ }^{84}$ Der Exotismus umfasst dabei mehrere Bereiche und Spielarten, indem der „Exot“ sich verschiedenen Phänomenen gegenüber gestellt sehen kann (z.B. der Erkenntnis, dass die Außenwelt, die Natur nicht zum eigenen Ich gehört; jedoch auch unterschiedlichen Räumen und Völkern, unterschiedlichen Zeiten und deren jeweiligen unterschiedlichen Wertsystemen). ${ }^{85}$

\section{Voix mortes: musiques Maori}

Am 15. Oktober 1907 erschien - u.a. dank einer Empfehlung Debussys, dem der Artikel auch gewidmet ist - im Mercure Musical ein Aufsatz Segalens, ${ }^{86}$ der sowohl anhand eigener, drei Jahre zuvor gesammelter Reiseeindrücke, als auch anhand musikethnographischer Literatur die Eigenart und das Schicksal der Maori-Musik behandelt. Musik bei den Maori, das bedeutete Segalen zufolge allgegenwärtigen Gesang, eine Freude am reinen Klang, an Tönen, die sich auch schon in der klangvollen Sprache dieses Volkes bemerkbar mache. Jedoch auch ganz ohne Worte, um des reinen Erklingens willen, werde dort Gesang, z.B. in langen Vokalisen, gepflegt (wie sie Segalen seinem Orpheus zum Beginn der Oper in den Mund legte). ${ }^{87}$ Diese sehr

79 Ebd.

80 Ebd., S. 41.

81 Ebd., S. 43.

82 Ebd., S. 44.

83 Ebd.

84 Ebd., S. 44.

85 Segalen: Ästhetik, S. 43-48, listet als mögliche Exotismen z.B. auf: Individualismus, Natur, Pflanzen und Tiere, Räume, (Menschen-)Rassen (er zieht die Möglichkeit von Außerirdischen in Betracht), Wertsysteme, Geschlechter, Zeit (Vergangenheit, Zukunft), denkt jedoch später (S. 50) auch an einen Exotismus wie denjenigen zwischen physischer und moralischer Welt.

86 „Max-Anély“" „Voix mortes: musiques maori“, in: Le Mercure Musical, 15. Oktober 1907, S. 1005-1027, wiederabgedruckt bei Joly-Segalen: Segalen et Debussy, S. 153-183.

87 Debussy träumte davon, Orpheus die ganze Oper über ohne Worte singen zu lassen, erkannte jedoch sogleich: „Mais ceci est une utopie irréalisable“ (Protokoll vom 12. November 1907; JolySegalen: Segalen et Debussy, S. 84). Laut einer Ankündigung Debussys im "Courrier musical" vom 1. Mai 1910, S. 379-380, hatte er immerhin noch die Absicht, Orpheus zu Beginn ganz ohne Orchesterbegleitung singen zu lassen, „(...) ce qui serait une nouveauté. Vgl. dazu auch Joly-Segalen: Segalen et Debussy, S. 81. 
eigene, ursprüngliche Musik sei dann jedoch im Gefolge der Missionierung fast vollständig abgetötet worden. Auch wenn die Maori inzwischen dabei seien, die Elemente dieser ihnen eigentlich fremden, da importierten Musik ihrem eigenen Geschmack anzupassen, so werde die ihnen ureigene Musik dadurch doch verfälscht und verdrängt. Zum Beschluss des Artikels entwirft Segalen die Fantasie der unerhörten Musik, die entstünde, wenn dem Volk der Maori die Möglichkeiten eines modernen Orchesters zu Gebote stünden: Klänge von solcher Gewalt würden hervorgebracht, „dass der freie Himmel zerbirst und sich auflöst“ (vgl. hierzu die Schilderung der Macht der Musik im III. Akt des Orphée-Roi sowie Debussys ähnlich gelagerte Idee einer Archaik und Moderne verbindenden Musik).

\section{Siddharta}

Nachdem Segalen sich Debussy am 25. April 1906 persönlich vorgestellt hatte (der Komponist hatte zuvor bereits durch seine Veröffentlichungen im Mercure de France Notiz von dem Autor genommen), überreichte er ihm bei dem Folgetreffen den Text zu einer möglichen Oper, sein Drama Siddharta. Debussy bewahrte demgegenüber jedoch eine ablehnende Haltung und verwarf das Buch im August 1907 schließlich auch als unvertonbar. Trotz des Schlussstrichs, den Segalen und Debussy dann anlässlich eines Gesprächs am 10. Oktober 1907 unter das Siddharta-Vorhaben zogen ${ }^{88}$ (Debussy, der bereits zwischen 1895 und 1900 zusammen mit Paul Valéry ein experimentelles "Orphée"-Ballett geplant hatte ${ }^{89}$ schlug daraufhin den Orpheus-Stoff vor), scheint dem Schriftsteller doch so viel an dem (selbst in der Dramenfassung noch ersichtlich) als Oper geplanten Text gelegen zu haben, ${ }^{90}$ dass er einzelne Motive und Details daraus rettete und in den Orphée-Roi übernahm. Wie Orpheus, so erscheint auch Siddharta nicht als Gott oder auch nur als göttlich Entrückter, sondern als Held, als Ausnahmemensch. Und ähnlich wie im Orphée$R o i$ konstruiert Segalen auch im Siddharta einen Dualismus, wobei der materiellen, sicht- und fühlbaren Welt der Sänger-Oper hier die Sphäre der vergänglichen Freuden und Schmerzen korrespondiert, während die geistige, immateriell-keusche Welt der Klänge im Orphée-Roi ihr Korrelat in dem jenseitigen, reinen Kreis des Nirwana findet, in das Siddharta zuletzt gelangt. Aus dieser Affinität zu diesen jeweils reinen, keuschen und geistigen Sphären resultiert dabei zugleich in beiden Werken eine Art der Wahrnehmung, durch die sich die Titelhelden je von den gewöhnlichen Menschen unterscheiden: Beide leben bereits zum Teil in anderen Welten und verfügen daher über ein anderes, weiter entwickeltes Sensorium. So erkennt Siddharta seine geliebte Cousine Krisha (wie später Orpheus Eurydike) nur

88 Vgl. Joly-Segalen: Segalen et Debussy, S. 79.

89 Orledge: Debussy and the Theatre, S. 260 u. 312. Aus diesem nie verwirklichten Plan erwuchs später das - ebenfalls unrealisierte - Projekt zu einer Oper mit einer Orpheus sehr verwandten Titelfigur: „Amphion“.

$90 \mathrm{Vgl}$. nur die Schlussszene mit seinen sich beständig überlagernden und murmelnden Stimmen sowie insbesondere der "choeur universel“, der angestimmt wird; vgl. Victor Segalen: Siddharta. Limoges 1974, S. 114. 
an ihrer Stimme, ohne ihr Gesicht auch nur zu sehen - nicht er jedoch, so legt das Drama nahe, ist blind, sondern all die anderen Menschen sind es, die nicht befähigt sind, die höhere, „wahrere“ Realität zu erkennen. Siddharta weist sich damit, ebenso wie Orpheus, als das aus, was Segalen unter einem „Exoten“ versteht: Sie erleben die Dinge der Welt anders und geraten daher mit den herkömmlich wahrnehmenden Menschen in Konflikt. Interessanterweise überträgt sich nun in beiden Werken die veränderte Art der Wahrnehmung auch auf das Drama selbst, welches jedes Mal eine Art von Gesamtkunstwerk vorzustellen versucht, indem darin synästhetische Momente inszeniert werden sollen (Orpheus, der in seinem Gesang erstrahlt; bei Siddharta das starke Ineinandergreifen von Sehen, Hören, Riechen und Empfinden). In der Tat hatte sich Segalen in einem im April 1902 im Mercure de France veröffentlichten Aufsatz „Les synesthésies et l'école symboliste“ vehement für die Möglichkeit und Realisierung synästhetisch konzipierter Kunstwerke eingesetzt. Im Rahmen seiner Exotismus-Theorie (die ja gerade von der scharfen Abgrenzung der fünf Sinne gegeneinander ausgehen muss) hatte er sich genötigt gesehen, diese Schrift dann zu widerrufen. ${ }^{91}$ Doch auch wenn Segalen damit letztendlich die Möglichkeit negierte, dass der Eindruck eines Sinnesorgans durch den eines anderen Sinneswerkzeugs ersetzt bzw. sogar überboten werden könnte, so kreiste sein Denken auch und gerade im Rahmen seiner Exotismus-Theorie weiter um eine andere, gesteigerte Art der (Sinnes-)Wahrnehmung. Und nicht nur auf der Ebene der Handlung und der Figuren (vgl. z.B. die Figur der Krisha, die große Ähnlichkeiten mit derjenigen der Eurydike hat), ${ }^{92}$ sondern auch hinsichtlich des ganzen Verfahrens, sich mit den verschiedenen Quellen und Überlieferungen eines Mythos auseinander zu setzen, um sie dann gemäß der eigenen Intention umzuformen, weisen Siddharta und Orphée-Roi deutliche Parallelen auf.

\section{4. "Dans un monde sonore“}

„Dans un monde sonore" ist eine sehr gute Sache, in einem bislang noch vollkommen unerkundeten Bereich... (...) Glauben Sie nicht, dass man etwas Bewundernswertes mit dem Mythos des Orpheus machen könnte? (...) Diese Überlegungen kamen mir während der Lektüre von „Dans un monde sonore“, wo Sie sich des Orpheus in einer Art und Weise bedienen, die zeigt, dass Sie den Mythos gut kennen. ${ }^{93}$

- mit diesen Worten führte Debussy in einem Brief vom 26. August 1907, in dem er zugleich seine Ablehnung des Siddharta-Dramas formulierte, den Orpheus-Stoff in das Opern-Projekt ein. ${ }^{94}$ Zunächst scheint Segalens in der am 16. August 1907

91 Vgl. Segalen: Ästhetik, S. 63.

92 Ähnlich wie Eurydike ist sie allein fähig, den flüchtenden Protagonisten zu verfolgen und aufzufinden; beide Frauengestalten "verschmelzen" schließlich auch mit dem Titelhelden.

93 Übersetzt nach Joly-Segalen: Segalen et Debussy, S. 67.

94 Dieser Funktion der Novelle als Keim des Opern-Librettos erweist Segalen auch im V. Akt Reverenz, wenn er den Kitharoden den Titel der Novelle zitieren lässt: „Aie pitié (...) De tes fils dans un monde sonore, Orphée! Orphée-Roi!“, Joly-Segalen: Segalen et Debussy, S. 338. 
im Mercure de France unter dem Pseudonym „Max-Anély“95 publizierten Novelle Dans un monde sonore ${ }^{96}$ mit dem Mythos des Sängers wenig zu tun zu haben; vielmehr berichtet in ihr ein Ich-Erzähler von seinem Besuch bei einem befreundeten Ehepaar, André und Mathilde, das sich auf eigentümliche Weise voneinander entfremdet hat. Denn beide, Mathilde (der gegenüber der Erzähler Ehebruchsgedanken hegt) wie André, stellen sich gegenseitig als verrückt dar. Im zunehmenden Maße offenbart sich ein Dualismus, der die jeweiligen Lebensgewohnheiten betrifft: Während André sich in einem fast dunklen Zimmer einschließt, wo raffinierte, synästhetische Instrumente (wie z.B. singende Lichtquellen) herkömmliche Klangphänomene bereichern und verstärken, lebt Mathilde in der herkömmlichen Welt der primären Seh- und Tasterfahrung. Im Verlauf der Novelle - und auf diese Passage beziehen sich Debussys Zeilen - gibt André dann in Form einer Kosmogonie-Erzählung eine Erklärung dafür, weshalb er die Welt fast nur noch hörend wahrnehmen kann und will: Die Welt sei ursprünglich aus Klängen erschaffen worden, während die träge Materie erst später, als eine Art Ablagerung oder sogar Dekadenzerscheinung hinzugekommen sei. ${ }^{97}$ In diese solcherart verstummende, da von starrer Stofflichkeit beherrschte Welt sei nun Orpheus gekommen, um den Menschen die Klangwelt wieder zu entdecken: So habe er die Felsen zum Klingen, die Tiere zum Lauschen gebracht. Als er sich in Eurydike verliebte, habe er versucht, sie aus der stummen Welt zu erlösen; sie aber habe ihn nicht verstanden, sondern seine reine Liebe für Begierde gehalten und - im Schlamm liegend, von Materie umgeben - ihr Kleid für ihn geöffnet. Er aber habe daraufhin die Flucht ergriffen... André identifiziert nun Mathilde mit Eurydike, sich selbst hingegen mit Orpheus (zumal dieser keine individuelle Persönlichkeit, als vielmehr ein Symbol, eine Personifikation der Sensibilität für die Phänomene eines fast immateriellen Klangkosmos gewesen sei). ${ }^{98}$ Der (inzwischen von seinen EhebruchsGedanken abgebrachte) Erzähler wird mehr und mehr selbst von der Idee einer akustischen Welt gepackt und versucht, sie auch theoretisch zu fundieren. Als er das Ehepaar jedoch nach einiger Zeit wieder besucht, scheint Mathilde gesiegt zu haben: André erklärt sich für geheilt, seine Erfahrung der „anderen, klingenden Welt" betrachtet er nun hingegen als eine krankhafte Phantasie, seine Erzählungen hierzu als „balivernes“: „Quatsch“.

Mit der Novelle, vor allem jedoch mit der den Orpheus-Mythos umdeutenden Kernerzählung Andrés, ist ein Korrelat zu dem Opernprojekt gegeben, mit dem

95 Vgl. dazu Kushner: Le mythe d'Orphée, S. 139.

96 Wiederabgedruckt bei Joly-Segalen: Segalen et Debussy, S. 189-215.

$97 \mathrm{Zu}$ dieser Art von Kosmogonie, die in vielen Schöpfungsmythen (nicht nur von Naturvölkern, wo Segalen ihr wahrscheinlich erstmals begegnet ist) zu beobachten ist, vgl. u.a. Marius Schneider: Singende Steine. München 1978, S. 11-20, wo Beispiele südamerikanischer, altasiatischer, afro-asiatischer Naturvölker sowie die Maori Neuseelands angeführt werden.

98 Diesen Gedanken nimmt Segalen auch dezidiert in das Vorwort zum Opern-Libretto auf (JolySegalen: Segalen et Debussy, S. 220), wenn er dort einen Gedankenaustausch mit Debussy referiert: „Orpheus war kein Mensch, und auch kein lebendes oder totes Wesen. Orpheus: die Sehnsucht, zu hören und gehört zu werden. Die Macht in einer klingenden Welt." 
der dort nur angedeutete Dualismus klar gedeutet und gewertet wird: Sehen und Tasten gelten hier wie dort als eigentlich primitive, schwache, verfälschende und unreife Wahrnehmungsarten, Hören hingegen wird als eine Sinnesqualität vorgestellt, die den fortentwickelten, zivilisierten Geistes-Menschen gemäß ist. ${ }^{99}$

\section{Exotismus und Ästhetik des Diversen}

In einer 1916 anlässlich der Publikation seines Buches Peintures verfassten Presseankündigung schrieb Segalen über sich selbst:

Der Exotismus, verstanden als eine Ästhetik des Diversen, ist im übrigen die zentrale, alles beherrschende Thematik, aus der sämtliche Bücher, die Victor Segalen geschrieben hat (...) ihre Existenzberechtigung herleiten. ${ }^{100}$

Wie oben festgestellt, bedingt Segalens Exotismus-Konzept eine dualistische Struktur, bei der es um die Mittlerschaft von Gegensätzen geht, die jedoch nicht aufgelöst oder aufgehoben, sondern ganz im Gegenteil bestehen bleiben sollen. Eben eine solche Opposition lässt sich auch im Orphée-Roi mit seinem Gegensatz zwischen stummer, materiell-sinnlicher Ding-Welt und klangvoller, geistig-reiner Ton-Welt beobachten.

Das Aufeinanderprallen unterschiedlicher Wertsysteme. Was für herrliche Dramen (...) resultieren daraus! ${ }^{101}$

Orpheus: das ist bei Segalen der Anders-Seiende, der Exot. ${ }^{102}$ Künstler, Schöpfer, Erfinder (vgl. die von ihm erhöhte Saitenzahl der Lyra und seine unerhörten Gesänge), ${ }^{103}$ der in einer Klangwelt lebt und die Macht der Musik beherrscht.

99 Die Idee einer solchen, sich entwickelnden und vom Materiellen zum Immateriellen fortschreitenden, qualitativ gewerteten Welterfahrung war um diese Zeit offenbar gerade verbreitet. Aby Warburg z.B., der diesen Gedanken aufgriff, hatte ihn wohl durch August Schmarsow, vor allen Dingen mittels dessen Aufsatz „Kunstwissenschaft und Völkerpsychologie: Ein Versuch zur Verständigung" (in: Zeitschrift für Ästhetik und allgemeine Kunstwissenschaft, Vol. 2, Stuttgart 1907, S. 305-339 u. S. 469-500; vgl. hier bezüglich der „höheren“ und „niedern “ Sinne sowie deren Entwicklung insbesondere die S. 315, 319, 321, 322) kennen gelernt. Vgl. hierzu Ernst H. Gombrich: Aby Warburg. Frankfurt a.M. 1984, S. 41 u. 62.

100 Segalen: Asthetik, S. 99.

101 Ebd., S. 46.

102 Auf ihn trifft der von Segalen: Ästhetik, S. 47, unterschiedene parasensorische Exotismus zu: „(...) die Gestaltung einer Welt, die sich von der unsrigen durch die Wahl der vorherrschenden Sinneswahrnehmung unterscheidet (Klangwelt, Geruchswelt usw.) (...)“.

103 Dies ein Motiv, das an der Orpheus-Figur bereits in Mittelalter und Renaissance betont wurde; vgl. dazu z.B. die Beiträge von Patricia Vicari: „Orpheus among the Christians" und John Warden: "Orpheus and Ficino" in: John Warden (Hg.): Orpheus - The Metamorphoses of a Myth. Toronto 1982, sowie Konrad Ziegler, Artikel „Orpheus“, in: Paulys Realenzyklopädie der classischen Altertumswissenschaft, Bd. 35, Stuttgart 1933, Kapitel IX, Spalten 1252-1254. Auch seine Einschätzung als Feigling durch den Krieger geht auf eine alte Tradition zurück: vgl. z.B. Emmet Robins: „Famous Orpheus“, in: Warden (Hg.): Orpheus, hier insbesondere S. 18-20. 
Dennoch ist er kein Gott oder göttliches Wesen, sondern (wie Segalens Siddharta) ein Held, ein Mensch, der sich durch sein Sensorium vor anderen auszeichnet, eben aber durch seinen menschlichen Anteil zugleich in der Lage ist, zwischen den beiden Welten zu vermitteln. Doch seine besondere Wahrnehmungsfähigkeit bringt ihn in doppelter Weise in Gegensatz zu seiner Umwelt: Da sind zum einen die Menschen, welche ihn - mit Ausnahme des Kitharoden und seiner Tochter Eurydike - nicht verstehen, da sie in einer groben, von roher Sinnlichkeit und Materie geprägten, starren Welt leben (vgl. auch deren Skepsis und Empörung gegenüber den von Orpheus eingeführten Neuerungen). Der Sänger versucht, ihre verarmte Welt zu bereichern und schöpferisch zu vollenden, indem er ihr seine Sensibilität für das Reich der Klänge gegenüberstellt. Aber wenngleich er sie mittels seiner Macht eine Zeitlang befrieden kann, vermögen sie es doch nicht, ihn zu verstehen - vielmehr versuchen sie, ihn nach ihren Begriffen (als Priester und/oder König) in ihre Gemeinschaft zu integrieren, ohne seine (und damit auch ihren eigene) Diversität, ihren gegenseitigen Exotismus akzeptieren zu können. Jedoch: "Selbst das Unverständnis der Menschen Orpheus gegenüber ist nichts als ein Moment des ewigen Dramas des Exotismus", schreibt Segalen 1908 in einem Brief an Max Prat. ${ }^{104} \mathrm{Um}$ mit Eurydike verschmelzen und dadurch die Welt verändern, bereichern zu können (vgl. die Myriaden von Stimmen, die daraufhin bei der Nennung ihres Namens erklingen), muss Orpheus selbst zu einem gewissen Grad menschlicher werden (vgl. seine "fast menschliche Stimme"105, seine Tränen), ebenso wie Eurydike ihre bisherige enge Menschlichkeit überschreiten muss (vgl. ihre freudige Entsagung gegenüber der herkömmlichen, irdischen Liebe). Zum anderen aber ist Orpheus der Mänade gegenübergestellt, deren schleimig-feuchtes Herrschaftsgebiet im Bauch der Erde das Reich der Materie, zugleich aber auch das der Entropie ist:

(...) ich stelle mir die Entropie wie ein Ungeheuer vor, noch schrecklicher als das Nichts. Das Nichts ist eisige Kälte. Die Entropie ist lauwarm. Das Nichts hat vielleicht die Härte eines Diamanten. Die Entropie dagegen ist eine lauwarme, breiige Masse, ${ }^{106}$

schreibt Segalen in seinen Aufzeichnungen und setzt „das Reich des Lauwarmen“, den „Moment des schleimigen Breis ohne Ungleichheiten, Unebenheiten oder Brüche" dann auch direkt in Beziehung zum Exotismus, wenn er schreibt, dass

104 Brief vom 23. Dezember 1908 - übersetzt nach Joly-Segalen: Segalen et Debussy, S. 109-110; Claude Debussy hingegen scheint dieses Spannungsverhältnis auch autobiographisch zu deuten und sich mit dem Sänger Orpheus zu identifizieren, wenn er am 27. August 1908 in einem Brief an Victor Segalen schreibt (Joly-Segalen: Segalen et Debussy, S. 102), dass der Anteil der Menge in dem Libretto erweitert werden müsse, um den Helden im Angesicht der „natürlichen Reizbarkeit der Masse gegenüber dem Genie" wachsen zu lassen. Fast genau ein Jahr zuvor, am 26. August 1907, hatte Debussy Orpheus in einem Brief an Segalen als „den Ersten und den Feinsten aller Unverstandenen " bezeichnet (Joly-Segalen: Segalen et Debussy, S. 67).

105 III. Akt, Joly-Segalen: Segalen et Debussy, S. 284

106 Segalen: Ästhetik, S. 82. 
"der Verfall des ethnographischen Diversen bereits eine blasse Vorahnung" von dieser Entropie gebe. ${ }^{107}$

Zugleich aber steht das breiige Reich der Mänade auch für die Region des Realen, jenen Aspekt der Materie, der dem Imaginären, Geistigen gegenüber steht:

Das Erfundene ist das Weiße-Männliche, der tausendfarbige Hauch. Das Reale wird das Schwarze-Weibliche sein, eine Masse aus Nacht. Das Reale wird mir immer als sehr weiblich erscheinen. (...) Die Materie ist weiblich. ${ }^{108}$

Von daher provozieren die Orpheus mit sich fortreißenden Mänaden am Schluss auch eine „schwarze Welle, die alles verschlingt “. ${ }^{109}$ Allerdings setzt Segalen diese Zuweisungen (weiß: männlich, schwarz: weiblich) nicht zu absolut - so erscheinen die Mänaden im Moment ihres Hereinbrechens noch (obgleich weiblich) als eine "immense bunte und weiße Woge", ${ }^{110}$ da in diesem Augenblick dem Imaginären, den unterschiedlichen Arten und Weisen, wie sich die Handlung fortsetzen könnte, noch alle Möglichkeiten offen stehen - erst, nachdem sie Orpheus mit sich gerissen und somit reale Tatsachen geschaffen haben, erscheinen sie als die besagte schwarze Welle.

Wenn Segalen im Orphée-Roi ferner Partei für das rein Geistige zu nehmen scheint, während er das Real-Materielle zuletzt doch unterliegen lässt, so geschieht dies in der Absicht, für die Macht des Seltenen, Ungewöhnlichen, Anderen einzutreten, das die Wahrnehmung der Welt zu bereichern imstande ist. Denn sein vorrangiges Interesse war es hier ja gerade, die vielfältige Schönheit der Welt im Aufeinanderprall des Ungewöhnlichen, Diversen mit dem Gewöhnlichen, Einheitlichen aufleuchten zu lassen, wodurch beide verwandelt werden. Bildhafter Ausdruck dieser wechselseitigen Befruchtung, welche zwar zwischen den Extremen vermittelt, sie jedoch nicht auflöst, ist dabei die Verschmelzung von Orpheus und Eurydike im III. Akt, durch die beide unsterblich werden, ${ }^{111}$ obgleich sie am Ende der Geschichte scheinbar - in den Augen der materieverhafteten Menschen - tot sind. Dies erklärt zum einen die zentrale Stellung des III. Akts im Gefüge des Dramas sowie die kompositionelle Zusammengehörigkeit von III. und V. Akt (Epilog): Eine Analyse von Komposition und Struktur des Schauspiels zeigt nämlich (vgl. das Schema weiter unten), dass sich die fünf Akte symmetrisch um den zentralen III. Akt gruppieren, der zusätzlich insofern von den übrigen hervorgehoben ist, als er aus einer einzigen Szene besteht und Mittags spielt (alle anderen Akte

107 Ebd., S. 95.

108 Victor Segalen: Aufbruch in das Land der Wirklichkeit (Equipée - Voyage au pays du réel, 1924). Frankfurt a.M. 1984, S. 45.

109 V. Akt, Joly-Segalen: Segalen et Debussy, S. 340.

110 V. Akt, Joly-Segalen: Segalen et Debussy, S. 339.

111 Die damit gegebenen, zwar deutlichen, doch zugleich reflektierten Parallelen zum Liebestod aus Wagners „Tristan“ waren es wohl auch, die Debussy so begeistert auf den „ekstatischen Tod“ der Eurydike reagieren ließen (Brief Segalens an seine Frau vom 8. Mai 1908, Joly-Segalen: Segalen et Debussy, S. 98), da er so seine Chance sah, mit Wagner in einen direkten musikalischen Wettstreit zu treten. Zur Parallelität von Debussys „Orpheus“- und „Tristan“-Projekten siehe ebd. 


\begin{tabular}{|c|c|c|c|c|c|}
\hline$\underline{\text { Akt }}$ & $\begin{array}{l}\text { Prolog/ } \\
\text { I. Akt }\end{array}$ & II. Akt & III. Akt & IV. Akt & $\begin{array}{l}\text { V. Akt/ } \\
\text { Epilog }\end{array}$ \\
\hline$\underline{\text { Zeit }}$ & $\begin{array}{l}\text { Früher } \\
\text { Morgen }\end{array}$ & $\begin{array}{l}\text { Nacht und } \\
\text { Morgen }\end{array}$ & Mittag & Nacht? & Tag \\
\hline Ort & Gebirge & Wald u. Fluss & $\begin{array}{l}\text { Säulenhalle/ } \\
\text { Meer }\end{array}$ & \begin{tabular}{|l} 
Unter \\
der Erde
\end{tabular} & Gebirge \\
\hline$\underline{\text { Szenen }}$ & 2 (3) Szenen & 3 Szenen & 1 Szene & \begin{tabular}{|l|}
2 Szenen + \\
1 „Interlude“
\end{tabular} & 1 Szene \\
\hline$\frac{\text { Verbin- }}{\underline{\text { dung }}}$ & $\begin{array}{l}\text { durch: } \\
\text { Einheit von } \\
\text { Zeit, Ort und } \\
\text { Handlung } \\
\text { Verwandlung } \\
\text { zw. Szenen } \\
\text { (fließender } \\
\text { Übergang } \\
\text { von Prolog } \\
\text { zu 1. Akt) }\end{array}$ & $\begin{array}{l}\text { durch: } \\
\text { Einheit von } \\
\text { Zeit und Ort } \\
\text { Verbindende } \\
\text { Zwischen- } \\
\text { spiele } \\
\text { (fließender } \\
\text { Übergang } \\
\text { zw. Szenen) }\end{array}$ & $\begin{array}{l}\text { HÖHE- } \\
\text { PUNKT: } \\
\begin{array}{l}\text { Lediglich } \\
\text { einszeniger } \\
\text { Akt }\end{array} \\
\text { Einziger } \\
\begin{array}{l}\text { Akt, der } \\
\text { mittags } \\
\text { spielt }\end{array} \\
\begin{array}{l}\text { Einziger Akt } \\
\text { mit nur zwei } \\
\text { Personen }\end{array}\end{array}$ & $\begin{array}{l}\text { durch: } \\
\text { Einheit von } \\
\text { Zeit und } \\
\text { Handlung } \\
\text { Verwandlung } \\
\text { Akterset- } \\
\text { zendes } \\
\text { "Interlude“ } \\
\text { Fliessender } \\
\text { Übergang } \\
\text { zw. Szenen } \\
\end{array}$ & $\begin{array}{l}\text { SCHLUSS: } \\
\begin{array}{l}\text { Lediglich } \\
\text { einszeniger } \\
\text { Akt }\end{array} \\
\text { Rückkehr } \\
\text { zum Ort des } \\
\text { 1. Aktes }\end{array}$ \\
\hline
\end{tabular}

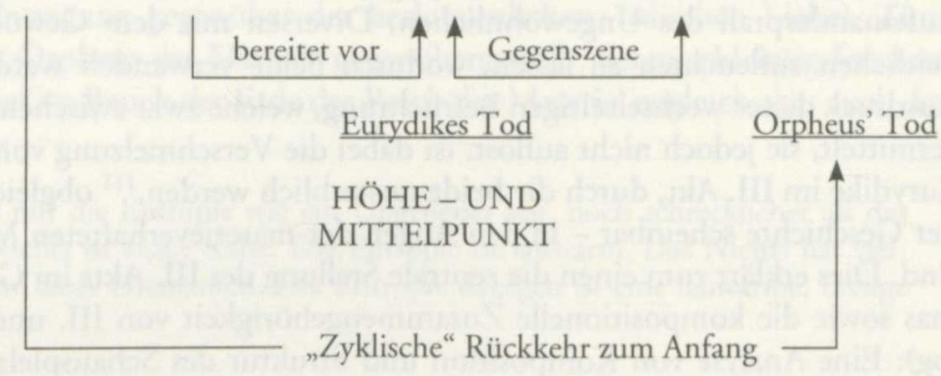

spielen nachts oder morgens). Zusätzlich erweist er sich als der einzige Akt, in dem lediglich zwei Personen auftreten. ${ }^{112}$ Das Drama ist zugleich zyklisch angelegt, denn dem III. Akt vergleichbar wird der epilogische V. Akt dadurch hervorgeho-

112 Vorbereitet wird der zentrale III. Akt durch den vorangehenden II., in dem Orpheus und Eurydike nicht nur den Höhepunkt ihrer Entfremdung voneinander erleben (insofern fungiert der II. Akt zugleich als Gegensatz zum III. Akt), sondern Eurydike auch im Gespräch mit ihrem Vater eine Vorahnung ihres „Todes“ befält. Als diametral entgegen gesetztes Element zum III. Akt hingegen wirkt der nachfolgende IV. Akt, wobei die (von Orpheus bezeichnenderweise auch zunächst für Eurydike gehaltene!) Gestalt und das Verhalten der Mänade sowie ihr realer Tod im Kontrast zu Gebaren und Schicksal der Eurydike stehen. Auch Kushner: Le mythe d'Orphée, S. 147, versteht die Mänade als „métamorphose diabolique d’Eurydice" bzw. spricht S. 156 von „deux Eurydices“. 
ben, dass auch er aus einer einzigen Szene besteht; darüber hinaus kehrt mit seiner Szenerie („das Gebirge“) diejenige des Prologs bzw. I. Akts wieder ${ }^{113}$ (vgl. auch den Hinweis im Einleitungstext zum V. Akt selbst: „[...] das Gebirge - das Gleiche, wo vor wenigen Monaten... vor wenigen Tagen... vor wenigen Augenblicken"). Mit dem zweiten „Höhepunkt" der Oper - dem Verschmelzen der Stimme des Orpheus mit seinem Instrument, seinem Tod und seiner Apotheose, symbolisiert durch den Aufstieg der Lyra ${ }^{114}$ - mündet der Schluss der Oper in ihren Anfang ein, damit möglicherweise die Unendlichkeit des „ewigen Dramas des Exotismus" sowie den bereits in „Dans un monde sonore“ formulierten Gedanken suggerierend, dass es sich bei Orpheus nicht um eine einzige Person, sondern vielmehr einen von vielen Individuen verkörperten Typus im Verlauf der Menschheitsgeschichte handele. Wie zuvor Eurydike im III. Akt geht Orpheus daher im V. Akt scheinbar in den Tod, um so den "Sieg des Geistes über all das grobe Zeitliche ${ }^{\text {"115 }}$ zu erringen und zu vollenden. Orpheus - im ursprünglich geplanten Titel durch das Epitheton "triomphant" ausgezeichnet ${ }^{116}$ - erscheint hier, in dieser Uminterpretation des mythologischen Stoffes, als durch und durch siegreich und königlich.

\section{Diesseits und Jenseits des Mythos}

Im Gesamtwerk Segalens nimmt der Orphée-Roi eine (bislang nicht beachtete) Sonderstellung ein - dies nicht nur insofern, als er das einzige, in Abhängigkeit und Zusammenarbeit mit einem anderen Künstler entstandene Werk ist, das zudem viele Facetten der anderen Werke Segalens in sich trägt; darüber hinaus stellt das Libretto einen zweifachen Höhepunkt im Schaffen des Autors dar. Denn zum einen markiert die Figur des Orpheus für ihn einen (wie Segalen es in einer Notiz auf dem Manuskript vermerkt hat) „Höhepunkt des Exotismus“, ${ }^{117}$ indem er in Segalens Interpretation geradezu als die Personifikation der bis ins Extrem gesteigerten Alterität gelten kann:

(...) nur im Unterschied liegt der Reiz. Je feiner und unscheinbarer der Unterschied, desto stärker erwacht und schärft sich der Sinn des Diversen, ${ }^{118}$

113 Der Prolog kann insofern zum I. Akt hinzugerechnet werden, als beide in der gleichen Szenerie spielen und ineinander übergehen; zusätzlich weisen alle Akte - mit Ausnahme eben des III. und V. Akts - je drei Szenen auf; das „Interlude“ des IV. Akts ersetzt auf Wunsch Debussys eine ursprünglich hier noch von Segalen vorgesehene Szene, deren Inhalt schließlich rein musikalisch repräsentiert werden sollte (vgl. Joly-Segalen: Segalen et Debussy, S. 327) - insofern weist auch der IV. Akt in gewisser Weise drei Szenen auf.

114 Zur Tradition dieses Motivs vgl. Ziegler: Artikel „Orpheus“, Kapitel XV.

115 Segalen: Aufbruch, S. 64.

116 Protokoll vom 10. Oktober 1907, Joly-Segalen: Segalen et Debussy, S. 78.

117 Vgl. die Notiz auf einer Seite des Libretto-Manuskriptes, abgedruckt z.B. bei Joly-Segalen: Segalen et Debussy, S. 269 sowie Meyers: „The opera that never was“, S. 502: „Le comble de l'exotisme: Les autres mondes, mondes sonores (...).

118 Segalen: Ästhetik, S. 86. 
notierte Segalen in seinen Aufzeichnungen. Gerade sein Orpheus differenziert sein ohnehin bereits von der üblichen Wahrnehmung abgesetztes, diverses Sensorium und verfeinert es, indem er nicht einfach die Welt nur akustisch geschärft wahrnimmt, sondern darüber hinaus synästhetisch, "mit all seinen Ohren sieht und mit all seinen Augen den Blick hört. "119

Zum anderen konnte Segalen hier - wie in sonst kaum einem anderen Werk den zeitlichen Exotismus auskosten, indem er mit seinem Libretto in eine weit entfernte, wild, archaisch und geheimnisvoll anmutende Epoche zurückführt, die noch vor der Formierung des Orpheus-Mythos liegt. „(...) diese primitiven Zeiten“, ,so jung und selbst so klar" ${ }^{\text {“120, }}$, geben ihm sogar die Möglichkeit, die aus den gewohnten Orpheus-Erzählungen bekannten Elemente zu versammeln, ${ }^{121}$ sie jedoch neu zu gruppieren und als scheinbar authentischer auszugeben als die - nun als verfälschend und sentimentalisiert ${ }^{122}$ dargestellten - tradierten Dichtungen mit ihrer Erzählung vom aus Liebessehnsucht in den Hades hinab gestiegenen Sänger, der dort seine Geliebte ein zweites Mal verliert. Doch nicht nur die Bildung solcher Mythen, sondern auch die Wandlungen, welche das Bild von Religionsstiftern im Zuge der über sie kursierenden Erzählungen und Berichte verzerren, werden von Segalen thematisiert, wenn er seinen Orpheus mit Christus parallelisiert - so sollte das „Interlude“ des IV. Akts auch schildern, wie die Menschen „den unerwarteten Häuptling feiern, der die Hölle besiegt hat, der aus jenem Ort wiederaufersteht, von wo noch niemals ein Mensch zurückgekommen ist"; auch die Berichte des Alten im sodann folgenden V. Akt, dass die Menschen sich für Orpheus gegenseitig umbringen, dass sie Fetzen seiner Tunika sammeln, seine Worte wiederholen und seine Schmerzen, seine Agonie nachspielen, verweist deutlich auf Riten und Konsequenzen der christlichen Religion. ${ }^{123}$

119 Segalen, Orphée-Roi, I. Akt,1. Szene, übersetzt nach Joly-Segalen: Segalen et Debussy, S. 243.

120 Segalen in einem Briefentwurf an Debussy vom 25. Oktober 1907, Joly-Segalen: Segalen et Debussy, S. 82.

121 Im I. Akt lässt Segalen den Priester die etymologischen Assoziationen zum Namen des Orpheus aufzählen, die mit „Dunkelheit“ assoziiert sind: „Orpheus - , der Schattenhafte'... Orpheus, ,der Dunkle‘... Orpheus, ,der Blinde vielleicht...“. Vgl. dazu u.a. Karl Kerényi: „Der Mythos von Orpheus und Eurydike“, in: Die Mythologie der Griechen, Vol. II: Heroengeschichten, 1966, zitiert nach Csampai u. Holland (Hg.): Claudio Monteverdi, Orfeo, S. 9-15, hier: S. 11: „Es war aber vielleicht nicht ungereimt und nicht ohne Absicht, wenn ein später Schüler des Sängers das dunkle Gewand des Orpheus, in dem er für die Argonauten der Hekate opferte, mit einem Wort bezeichnete, das von orphne, , die Dunkelheit' herststammt." Auch die Verwechslung von Eurydike und Mänade durch Orpheus ist mit etymologisch motiviert, bedeutet Eurydike doch Kerényi, S. 11, zufolge auch „die weithin Richtende: ein Name, der ursprünglich nur der Unterweltskönigin zukam (...)“. Als ebensolche bezeichnet sich die Mänade bei Segalen im IV. Akt: „Dies ist mein Reich! (...). Hier bin ich Königin." Vgl. Joly-Segalen: Segalen et Debussy, S. 321-325.

122 Vgl. dazu Anm. 68.

123 Anklänge an die Genesis des Alten Testaments weist hingegen der Spruch des Orpheus im III. Akt „Das Werk ist schön“ (Joly-Segalen: Segalen et Debussy, S. 304) auf, mit dem offensichtlich die guten Werke der Schöpfungstage überboten werden sollen. Bouillier: Victor Segalen, S. 163, liest die von Segalen formulierte Kritik sogar dahingehend, dass dieser damit die organisierte Kirche angreifen will: „Il est clair que pour lui le christianisme organisé en église méconnait égal- 
Segalen nutzt den zeitlichen Exotismus mithin auf raffinierte Weise, um in seinem Gefolge - und ganz im Sinne von Debussys Kritik an den anekdotischen und weinerlichen Lesarten früherer Opern ${ }^{124}$ - ein Zurückgehen auf die Urgründe des Mythos, eine Durchdringung der sich darauf abgelagerten Deutungsschichten zu simulieren.

\section{Das Verstehen des Nicht-Verstehens}

Damit wäre man wieder bei dem eingangs konstatierten Zyklus, der um Phänomene, deren Deutung und Interpretation und das stets neu erwachende Bedürfnis kreist, das so entstehende Palimpsest aus sich überlagernden Sinnzuweisungen zu durchstoßen, um wieder zu den Phänomenen selbst zu finden - und sie in der Folge dann wieder mit eigenen Deutungen und Interpretationen zu bedecken. Segalens Libretto jedoch verweigert sich diesem Kreislauf insofern, als es dieses „Ad fontes“ nur noch simuliert. Zwar strebt er an, „die bekannte Legende zu zertrümmern und die ewig nur wiedergekäuten Mythen zum Bersten zu bringen "125; er ist sodann jedoch nicht, wie er selbst betont, daran interessiert, die so gewonnenen Fragmente zu einer mythographisch korrekten Rekonstruktion der antiken Orpheus-Sage zusammenzulegen: ${ }^{126}$ „Den Mythos (so könnte man in Abwandlung eines Zitats von Hans-Thies Lehmann sagen) gilt es nicht zu verstehen, sondern in andere Verknüpfungen zu bringen, bis sie den verlorenen Verknüpfungen im Subjekt sich annähern" ${ }^{127}$ Segalen wollte sich insofern auch von der Vitalität und Ungezwungenheit der atavistischen, wilden und ,jungen “ Frühzeit leiten lassen, „die sich glücklicherweise gegen die dokumentarische Mechanik wehren, so dass man sie mit aller Freiheit der Intuition sehen und lieben kann. " ${ }^{128}$ Der OrpheusStoff war Segalen dann auch vor allem - die vorangegangenen Darlegungen haben es gezeigt - Anlass und Substrat zugleich, um seine eigenen Ideen Gestalt gewinnen

ment la grandeur propre du Christ. (...) Vénérer Orphée comme un dieu, c’est méconnaître son mérite surhumain, son génie artistique et spirituel."

124 Siehe Anm. 68.

125 Segalen in einem Briefentwurf an Debussy vom 4. September 1907, der mit „La Naissance d'Orphée" überschrieben ist, Joly-Segalen: Segalen et Debussy, S. 69, sowie Bouillier-Segalen, Correspondance, Vol. I, S. 711.

126 Segalen im Briefentwurf vom 25. Oktober 1907 an Debussy: Joly-Segalen: Segalen et Debussy, S. 83 sowie Bouillier-Segalen: Correspondance, Vol. I, p. 718; vgl. auch die Zitate bei Joly-Segalen: Segalen et Debussy, S. 13.

127 Lehmann: „Über die Wünschbarkeit“, S. 430, der von der Rede des Freudschen Patienten spricht.

128 Im Briefentwurf an Debussy vom 25. Oktober 1907, Joly-Segalen: Segalen et Debussy, S. 83, sowie Bouillier-Segalen: Correspondance, Vol. I, S. 718. Einem etwas späteren Briefentwurf (3. Januar 1908, weder bei Joly-Segalen noch den Oeuvres complètes wiedergegeben) an Debussy zufolge hatte Segalen sogar erwogen, eigens nach Griechenland zu reisen, um sich einen Eindruck vom Schauplatz seines Librettos zu verschaffen, doch dann entschied er sich dagegen, da seiner Meinung nach „allein im Imaginären die schönsten Dinge und solidesten Realitäten enthalten sind“. Vgl. dazu den Brief bei Bouillier-Segalen: Correspondance, Vol. I, S. 735-736. 
und präziser werden zu lassen. Die Figur des antiken Sängers eignete sich hervorragend, um „das Drama der lyrischen, vor allem sensoriellen, vielleicht auch religiösen Unverstandenheit“ eines „kreativen, erfinderischen, fortgeschrittenen Mannes im Kampf und in Opposition zu den anderen Menschen: den ,anderen “ ${ }^{129}$ " $\mathrm{zu}$ realisieren, und eben der Begriff der „Unverstandenheit“ (,incompréhension“) erweist sich zusammen mit seinem auch antonymen Wortfeldern (verstehen, Verständnis etc.) als das konstitutive Element des ganzen Librettos. ${ }^{130}$ Chiffren dieser zentralen Bedeutung des Verstehens sind der Umstand, dass die Handlung fast ausschließlich von gescheiterter, gestörter Kommunikation, von Fremdheit, Unverständnis, unmöglicher Vermittlung lebt, vor deren Hintergrund sich der geglückte Dialog zwischen Orpheus und Eurydike, ihre Harmonie, ihre nicht durch Verständnis, sondern über Gefühl und Entschlossenheit erreichte Übereinkunft und ihre schließliche Verschmelzung umso positiver abheben. Wie gesehen, bedurfte Segalen mit seinem Konzept einer Ästhetik des Diversen dieser Spannung zwischen einander fremden Welten und konnte nur ansatzweise und vorübergehende Vermittlungen zulassen.

Interessant ist es nun, die im Orphée-Roi einander gegenüber gestellten Welten von träger, stummer, nur tastend zu erfahrender Materie und lebendiger, klingender, synästhetisch sich vermittelnder Geisteswelt mit den Denkfiguren Gumbrechts zu fassen. Denn dieser weist nicht nur insofern gewisse Affinitäten zu Segalen auf, als auch er die Gewalt als eine Bedingung ästhetischen Erlebens postuliert; ${ }^{131}$ darüber hinaus bietet Gumbrecht indirekt eine mögliche Deutung für die synästhetischen Verweise in Segalens Libretto an. Ihm zufolge sind synästhetische Äquivalenzen im Kontext der im 19. Jahrhundert unternommenen Bemühungen zu verstehen, begrifflich vermittelte Erfahrung und sinnlich erlebte Wahrnehmung wieder zusammen zu führen, nachdem sich Worte und deren Klang von den damit bezeichneten Objekten längst abgelöst und entfremdet hatten. Dichter wie Verlaine oder Rimbaud hätten gegen die damit einhergehende zunehmende Abstraktion ihrer Gedichte vorzugehen versucht, indem sie „die Klangstrukturen ihrer Texte mit Bedeutungen - zumindest mit bestimmten konnotativen Bedeutungen -" erfüllt hätten; ${ }^{132}$ umgekehrt sei die besondere Typographie eines Mallarmé-Gedichts auf die Andeutung hin ausgerichtet, „dass die Anordnung der Worte des Gedichts auf dem Papier seinem Sinn und seinem

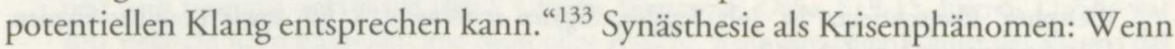

129 Joly-Segalen: Segalen et Debussy, S. 13.

130 Demgegenüber liest Kushner: Le mythe d'Orphée, S. 157, das Libretto - sich sehr viel weniger von der Handlung lösend - als „une allégorie de ,l'art pour l'art' en musique; la musique ne devrait avoir d'autre fonction que la sonorité pure".

131 Beide scheinen davon auszugehen, dass die ästhetische Erfahrung mit einer Art Resonanz zusammenhängt, die aus dem Zusammenprall zweier Entitäten resultiert: Bei Segalen sind dies das Ich und all die unterschiedlichen, das Nicht-Ich ausmachenden Phänomene; Gumbrecht: Diesseits der Hermeneutik, S. 135, spricht von einer „Raumbesetzung durch eine Substanz“.

132 Ebd., S. 59.

133 Ebd. 
Orpheus als „der, (...) welcher mit all seinen Ohren sieht und mit all seinen Augen den Blick hört", ${ }^{134}$ beschrieben wird - ist auch er dann als Idealentwurf eines Wesens gedacht, das die voneinander abgespaltenen Sphären von „Erfahrung“ und "Wahrnehmung" in sich wieder versöhnen und vereinen soll? Dass Segalens Orpheus deutliche Züge eines Mittlers aufweist, ist zuvor bereits bemerkt worden. Tatsächlich ließe sich der Protagonist des Opern-Librettos schließlich noch in anderer Hinsicht als ein Vermittler von bei Gumbrecht definierten Welten verstehen. Denn in der Mitte seines Buches listet der Autor Eigenschaften der zuvor voneinander abgegrenzten Sinn- und Präsenzkulturen auf, die sich „mutatis mutandis" mit dem von Segalen in seinem Orphée-Roi eröffneten Dualismus zwischen Materie und Geistwelt decken. Der Sinnkultur weist Gumbrecht ein Selbstverständnis zu, in dem der Mensch sich der Welt gegenüber als abgegrenzt, divers, exzentrisch begreift, da er sich vornehmlich als den körperlichen Dingen der Welt gegenübergestellter Geist wahrnimmt; folglich wird die Materie hier nur als ein Substrat für Geistiges betrachtet; die Welt soll umgestaltet, verschönert, ihre Rhythmen sollen verändert werden; daher wird eine Sinnkultur auch durch Innovationen geprägt. Ihr Ideal einer Weltaneignung lässt sich schließlich mit den Begriffen „Interpretation“ und „Kommunikation“ beschreiben.

Demgegenüber definiert sich der Mensch in der Präsenzkultur primär über seinen Körper, den er als Bestandteil der Welt empfindet; die Materie hat für ihn daher auch eine eigene Qualität, und er strebt nicht danach, die Welt und ihre Rhythmen zu verändern, sondern er versucht vielmehr, sich dem so vorgegebenen Takt einzufügen. Diesem Einswerden mit dem Kosmos entspricht auch eine Art der Weltaneignung, bei der die Dinge nicht geistig vermittelt, sondern körperlich erfasst, verzehrt und einverleibt werden. ${ }^{135}$

Einzig in ihrer Wertung unterscheiden sich Segalen und Gumbrecht: Wo bei diesem die Präsenzkultur positiv, die Sinnkultur hingegen negativer akzentuiert ist, da weist jener seine die bloße Präsenz transzendierende, sich nach Kommunikation sehnende Titelgestalt als positiven Helden aus.

Doch da Schönheit, Intensität, Lebendigkeit, Bereicherung bei ihm nur aus dem Zusammenprall der unterschiedlichen Bereiche erwachsen können, kommt es auch hier schon zu jenem eingangs beschworenen Oszillieren zwischen Präsenz- und Sinneffekten - und es ist vielleicht kein Zufall, dass es lange schon vor dessen theoretischer Formulierung in Gestalt eines (wenngleich nie zur Vertonung gelangten) ${ }^{136}$

134 Joly-Segalen: Segalen et Debussy, S. 243. Gumbrecht: Diesseits der Hermeneutik spricht, S. 118, von einem „nachgerade exzessiven, überschwänglich lieblichen Wonnegefühl“ beim Hören einer Mozartarie und beschreibt es als synästhetische Erfahrung, bei der sich Tast- und Gehörsinn verbinden (,$\ldots$ und ich tatsächlich glaube, die Oboe mit meiner Haut zu hören“).

135 Gumbrecht: Diesseits der Hermeneutik, S. 99-101.

136 Segalen schrieb zwischen 1907 und 1915 insgesamt drei Fassungen des Librettos; 1913 scheint Debussy noch an eine Realisierung der Oper geglaubt zu haben, 1915 stellte Segalen eine endgültige Fassung fertig, die er im Einverständnis mit Debussy als Publikation vorsah, ohne dass das Opernprojekt damit als gefährdet betrachtet wurde; doch in einem Brief an Segalen vom 5. Juni 1916 (Joly-Segalen: Segalen et Debussy, S. 141) stellt der Komponist das Vorhaben dann als mehr oder weniger aufgegeben dar; nach einer erneuten Lektüre des Text schreibt er: „Ich höre die 
Opern-Librettos vorgeführt wurde. Denn, wie Lehmann bezüglich des (insbesondere) antiken Theaters schreibt: „Verstanden wird hier, und hier erst recht, das Nichtverstehen (...) weil die Bühne stets ein Ort war, an dem der Schiffbruch des Verstehens erfahren wird. "137

Musik, die das Drama begleiten müsste, weniger und weniger. Abgesehen einmal davon lässt man Orpheus nicht singen, denn er ist der Gesang selbst - das ist ein falsches Konzept, und was uns bleibt, ist, ein Werk geschrieben zu haben, an dem einzelne Partien schön sind." Postum wurde der Text dann 1921 veröffentlicht. In Joly-Segalen: Segalen et Debussy, S. 141, wird interessanterweise darauf hingewiesen, dass Debussys Einwand, man solle Orpheus nicht singen lassen, bereits von Roger-Ducasse vorweggenommen wurde, der zwischen 1912 und 1913 ein „mimodrama lyrique "über den antiken Sänger komponierte, in dem Orpheus und Eurydike stumm blieben und lediglich tanzten, während allein der Chor sang. Zu den Fassungen Segalens vgl. Bouillier: Victor Segalen, S. 157 u. S. 160-161, zu Roger-Ducasse vgl. Laurent Ceillier: RogerDucasse, le musicien, l'oeuvre, Paris 1920.

137 Lehmann: „Über die Wünschbarkeit“, S. 431. 